\title{
Mental Health Dynamics of Interfaith Spirituality in Believers and Non-Believers: The Two Circuit Pathways Model of Coping with Adversities: Interfaith Spirituality and Will to Exist, Live and Survive
}

\author{
Ibrahim Kira ${ }^{*}$, Neslihan Arıcı Özcan², Hanaa Shuwiekh³ ${ }^{3}$ Justyna Kucharska4, \\ Amthal H. Al-Huwailah', Mireille Bujold-Bugeaud6 \\ ${ }^{1}$ Center for Cumulative Trauma Studies, Stone Mountain, GA, \& Center for Stress, Trauma and Resiliency, \\ Georgia State University, Atlanta, USA \\ ${ }^{2}$ T.C. İstanbul Medeniyet University, Istanbul, Turkey \\ ${ }^{3}$ Fayoum University, Fayoum, Egypt \\ ${ }^{4}$ University of Westminster, London, UK \\ ${ }^{5}$ College of Social Sciences, Kuwait University, Kuwait City, Kuwait \\ ${ }^{6}$ Center for Cumulative Trauma Studies, Stone Mountain, USA \\ Email: *kiraaref@aol.com, neslihan.ozcan@medeniyet.edu.tr, hanaashiwk2000@hotmail.com, \\ justyna_kucharska@yahoo.com, Alhuwailah.77@ku.edu.kw, kiraaref@gmail.com
}

How to cite this paper: Kira, I., Özcan, N. A., Shuwiekh, H., Kucharska, J., Al-Huwailah, A. H., \& Bujold-Bugeaud, M. (2021). Mental Health Dynamics of Interfaith Spirituality in Believers and Non-Believers: The Two Circuit Pathways Model of Coping with Adversities: Interfaith Spirituality and Will to Exist, Live and Survive. Psychology, 12, 9921024.

https://doi.org/10.4236/psych.2021.126060

Received: May 31, 2021

Accepted: June 27, 2021

Published: June 30, 2021

Copyright $\odot 2021$ by author(s) and Scientific Research Publishing Inc. This work is licensed under the Creative Commons Attribution International License (CC BY 4.0).

http://creativecommons.org/licenses/by/4.0/

\begin{abstract}
Objective: The study was designed to examine the differential effects of spirituality on the mental health of believers and non-believers coping with adversities. Method: Spirituality, "will to exist live and survive (WTELS)", cumulative traumas, perceived posttraumatic growth, psychopathology, existential anxieties, self-esteem, and reappraisal were measured in two samples of main believers (Egypt, Turkey, and Kuwait, $\mathrm{N}=1210$ ) and mostly nonbelievers (UK, $\mathrm{N}=178$ ). The study used path analysis supplemented by PROCESS macro and multigroup invariance to analyze the data. Results: identified two positive invariant coping paths for believers, one through WTELS and the other through spirituality. A similar positive path of WTELS, but not spirituality, was found in the non-believers. Conclusion: While believers and non-believers utilize their WTELS pathway to cope with adversities, the believers utilize the additional pathway of spirituality. The nonbelievers still utilize self-transcendence strategies of non-theistic or secular spirituality. The results have conceptual and clinical implications for developing differential prevention and intervention strategies.
\end{abstract}




\section{Keywords}

Believers and Non-Believers, Existential Anxieties, Psychopathology, Posttraumatic Growth, Interfaith Spirituality

\section{Introduction}

Coping with adversities may have different pathways in those who believe in a higher power, and those who may not believe. The differences between those who do not believe in a higher power, and the believers in their coping strategies with adversities, never have been studied. The goal is to fill some of these gaps in the literature by identifying the differential coping strategies for each group which helps individualize interventions as well as developing transdiagnostic strategies for those potentially shared coping strategies.

Striving to make sense of the meaning and purpose of a person's life project and existence is often experienced in tandem with severe and serious adversities and threats to personal or collective identities (e.g., terminal illness, oppression, Holocaust, and genocides). People who experience existential threats encounter a crisis of the meaning and purpose of life and existence. They may experience existential anxieties about the future of their survival (Davis et al, 2003; Frankl, 2000). Existential turmoil and spiritual crisis may lead either to spiritual struggle (Exline \& Rose, 2013) or spiritual growth (or both). Spirituality usually emerges as one outcome of this process. However, these dynamics may differ between believers and non-believers in a higher power. The differences in these dynamics between believers and non-believers (e.g., atheists) are poorly understood.

The model of value processing explains how cumulative adversities lead to post-traumatic growth (PTG). Cumulative adversities lead to increased cognitive dissonance, self-discrepancy, and existential anxieties. Cognitive dissonance and existential anxieties lead to initial automatic appraisal, followed by deliberate conscious reappraisal. Deliberate reappraisal leads to a recalibration of the person's belief and value processing system, followed by positive self-evaluation and improved mental health and PTG. WTELS is the core executive that motivates and operates this process (see Figure 1).

Exposure to cumulative life stressors and traumas (CST) are important parts of development and growing up emotionally and spiritually (Kira et al., 2013b). Perceived posttraumatic growth (PTG) (Tedeschi \& Calhoun, 1996) is associated with trauma, suffering, and PTSD non-linearly (Kanaan et al., 2019; Kira et al., 2013a). Severe CST that threatened the existence of one of the individual's personal, collective, status or physical identities and triggers existential annihilation anxieties (Kira et al., 2012c; Kira et al., 2019b), may lead to psychopathology, PTSD, and poor physical health. However, executive will to exist, live and survive (WTELS), a novel construct was recently introduced in the literature (Kira, et al., 2014a; 


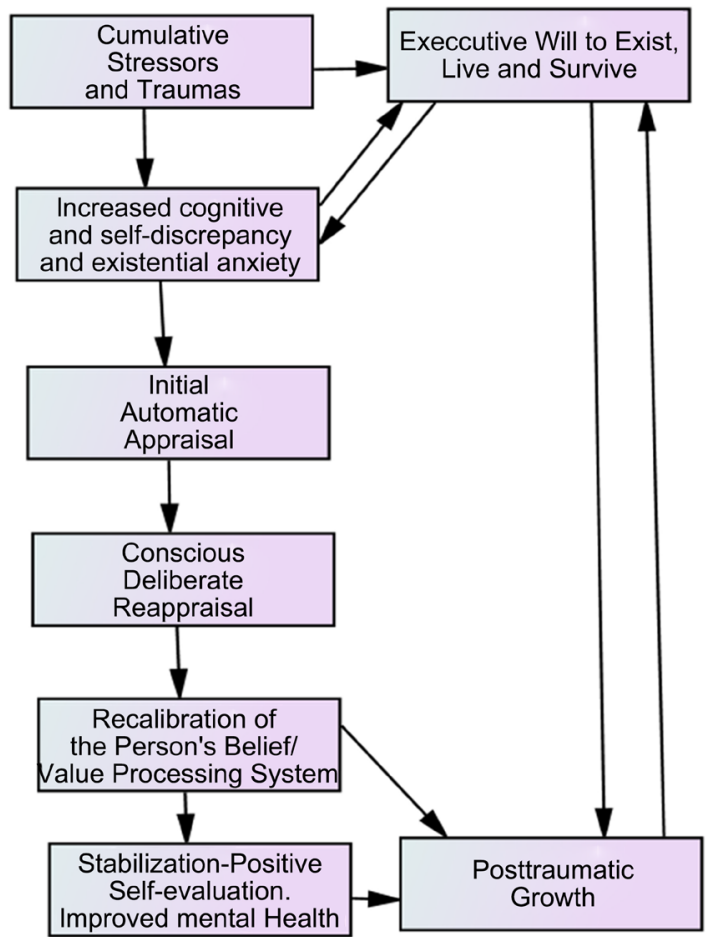

Figure 1. Trajectory chain of value processing of stressors and traumas and the pathway to postraumatic growth.

Kira et al., 2020a), along with self-esteem (positive self-evaluation) and emotion regulation strategies (e.g., reappraisal) and interfaith spirituality (Kira et al., 2019c) may be effective buffers against such existential anxieties to prevent the eruption of psychopathology and may lead further even to perceived posttraumatic growth (PTG). WTELS is the intrinsic, innate motivation or metamotivation to exist, live, survive, self-actualize, and succeed/thrive (Kira et al., 2020a). WTELS propels and manages goal-directed activities and their hierarchy of motivational architecture in different challenges and life projects. WTELS is an existential feature that is part of the person's agentic executive self (Kira et al., 2014a). WTELS, a non-cognitive (or pre-cognitive) factor, has cognitive, emotional, behavioral, and mental health consequences. WTELS is a powerful tool when it comes to the understanding of dynamics that are at the center stage in the science of motivation and coping with adversities. These dynamics include WTELS's role in mental and physical health, post-traumatic growth (PTG), resilience, seeking, and providing social support. The empirical research found compelling evidence that WTELS is strongly associated with PTG, resilience, and social support (Kira et al., 2020b). WTELS was found to be an effective coping strategy for severe prolonged and continuous traumas such as COVID-19 (Kira et al., 2021).

In this study, we will develop an inclusive model for interfaith spirituality; explore the dynamics behind the emergence and impact of interfaith spirituality that include the dynamics of meaning-making and self-transformation. We will explore the mechanism behind spirituality's positive effects on believers and the 
mediation of self-esteem and emotion regulation. We discuss the role of spirituality, along with and "will to exist live and survive (WTELS)", in buffering existential anxieties and alleviating psychopathology, and promoting perceived posttraumatic growth (PTG). Further, we will develop and test a structural model for the relationship between interfaith spirituality, life adversities (cumulative trauma), WTELS, emotion regulation, self-evaluation (e.g., self-esteem), and different aspects of mental health and perceived posttraumatic growth (PTG) in believers and non-believers. While most of the previous studies tested spirituality in a specific faith, or one of its dimensions, and mental health in believers, they never tested this relationship in different faith believers and non-believers. The goal was to see the differential coping pathway utilized by those who believe in religious orientation and those who do not believe.

Interfaith spirituality (IFS) includes the personal heuristics that people, regardless of their different belief systems, who believe in the existence of a sacred creating force, use to make sense of human's finite existence, and cope with existence-threatening events (Kira et al., 2019c). The main tenets of interfaith spirituality (IFS) acknowledge the presence of a creating force regardless of its specific nature. IFS consists of basic components: closeness to creating power, asceticism, meditation, and divine love (Kira et al., 2019c). IFS found to contribute to the alleviation of existential turmoil, anxieties, and related spiritual struggle. Interfaith (theistic) spirituality, as contrasted by non-faith (non-theistic) or secular spirituality includes the personal heuristics and narratives that people of faith, regardless of their different belief systems, who believe in the existence of a sacred creating force, use to make sense of humans' finite existence and cope to existence-threatening events. These heuristics and narratives derive from beliefs in a sacred higher power c.f., e.g., (Emmons, 2005; Pargament, 1999) and the ability of self-transcendence e.g., (Koltko-Rivera, 2006; Levenson et al., 2005). While the belief in a sacred power does not exist in the non-believers' beliefs, self-transcendence heuristics, the second part of spirituality can be basic in nonbelievers' secular spirituality and beliefs (Kira et al., 2019c).

The focus of the current study on interfaith spirituality (IFS) does not mean that non-theistic or secular spirituality that may utilize more self-transcendence strategies has a less or more positive impact on mental health. Separating and studying both kinds will help clarify the dynamics of each. We assume that IFS will not have the same effects on non-believers, except for the self-transcendence strategies component (for example asceticism) that may reflect itself differently in non-believers, compared to the believers and that secular spirituality may have different or similar dynamics for non-believers

\subsection{Conceptual Model of the Dynamics of Spirituality in Believers and Non-Believers}

Interfaith spirituality, cumulative life adversities, and executive will to exist, live, and survive (WTELS) were identified as the interacting predicting variables that may lead to the emergence of two or three interacting causal chains or coping 
trajectories in believers (and non-believers). In the first trajectory, life adversities intensify existential annihilation anxieties (EAA) that may lead to psychopathology (and potentially PTG). In the second interacting chain or trajectory, WTELS leads the positive sequential chain of increased self-esteem, emotion regulation, and better mental health in believers and non-believers. Interfaith spiritualty leads in believers an additional positive sequential chain. WTELS and spirituality, in believers, significantly contribute to lowering EAA and psychopathology; priming emotion regulation (reappraisal and suppression), positive self-evaluation (self-esteem), and perceived PTG. In other terms, EAA, emotion regulation, and self-esteem mediate some of the impacts of life adversities on perceived PTG and psychopathology (the outcome variables). EAA mediates the negative sequential causal chain that is triggered by identity traumas and cumulative life adversities. Emotion-regulation (reappraisal and suppression) and self-evaluation (self-esteem) mediate some of the positive effects of spirituality and WTELS on mental health and on reducing existential anxiety scores in the positive sequential trajectory. However, in non-believers, the causal chain of coping that starts with interfaith spirituality does not exist, or may partially exist through the self-transcendence components of spirituality or other mechanisms not included in the current model. In non-believers, interfaith spirituality does not have positive or negative effects on the outcome variables

\subsection{Hypotheses}

Hypothesis 1: Interfaith spirituality (IFS) is associated with reduced EAA, psychopathology, and predicts increased emotion regulation strategy of reappraisal, self-esteem, and perceived PTG, in believers regardless of their religious affiliations.

Hypothesis 2: Spirituality is associated with the agenetic WTELS in believers regardless of their religious affiliations.

Hypothesis 3: WTELS predicts lower EAA, psychopathology, and higher emotion regulation, self-esteem, and perceived PTG in believers and nonbelievers.

Hypothesis 4: Emotion regulation (reappraisal and suppression), and selfevaluation (self-esteem) mediate the positive effects of interfaith spirituality and WTELS on mental health and perceived PTG in believers regardless of their religious affiliations. They further mediate the effects of WTELS on mental health and perceived PTG in non-believers.

Hypothesis 5: EAA mediates the negative effects of cumulative trauma on the mental health of believers and non-believers. WTELS moderates the mediation.

Hypothesis 6: The conceptual model of the association (the direct and indirect effects) between Spirituality, WTELS, cumulative live adversity, and EAA, emotion regulation, self-esteem, psychopathology, and perceived PTG, is invariant across gender, age, and cultural groups in believers regardless of their religious affiliations? 


\section{Methods}

We utilized two samples; the first sample included non-Western countries (Egypt, Turkey, and Kuwait) that involve participants who are religious believers (regardless of the level of religiosity or religious affiliation). The goal was to check the research hypotheses and validate our model across three different countries (Egypt, Turkey, and Kuwait) and two different religions (Islam and Christianity). The second sample included participants from the UK whose majority does not identify with a religion. The goal was to explore the dynamics of the model among non-believers.

\subsection{The First Sample}

\section{Procedures}

The research was conducted with the approval of a university institutional review board (IRB), as a cross-cultural study. Participation was voluntary. Each participant was informed about the general goals of the study and signed informed consent to participate. The questionnaire took 45 - 60 minutes to complete. In the first sub-sample (the Egyptian sample), we used a purposive snowball sampling strategy using research team networks and mosques and church leaders. The data were collected from three Egyptian cities that may represent geographically and culturally the different mix in the Egyptian sub-cultures: Fayoum (Middle Egypt) $(\mathrm{N}=184)$, Qena (Upper Egypt) $(\mathrm{N}=210)$, and Giza/ Cairo $(\mathrm{N}=96)$, (which is mostly a melting pot of diversities) cities. Three research teams of graduate students in clinical psychology (a different team in each cite) collected the data under the direct supervision of their advisors. We increased the recruitment of Christians to enable the comparison between Muslims and Christian in this predominantly Muslim country. The questionnaire was administered to participants in person individually and in groups. The questionnaire was administered to participants starting the first week of October through the first week of December of 2017.

In the Turkey subsample $(\mathrm{N}=420)$, data were collected from students and faculty of Istanbul Medipol University and Istanbul Medeniyet University and their families. All participants were living in Istanbul, Turkey's largest city. Ethical permission to conduct the study was taken from the Social Sciences Ethics Committee of Istanbul Medeniyet University. All instruments were presented to participants through a paper-pen format. It took approximately 40 - 45 minutes to fill in the questionnaire. The process of data collection lasted for 6 months from February 2018 to July 2018.

In the Kuwaiti subsample $(\mathrm{N}=300)$, the research team consisted of 4 doctoral students with a professor in Psychology as a supervisor and project leader. The team members have been trained in conducting research and interviewing. The sample design was a purposeful quota sample to represent different age groups, students, and communities (50\% of students and $50 \%$ of community). The questionnaire was administered to college students using a group class administra- 
tion, while the community participants were interviewed personally.

\section{Participants}

We combined the three data sets from Egypt $(\mathrm{N}=490)$, Turkey $(\mathrm{N}=420)$, and Kuwait $(\mathrm{N}=300)$. The combined sample $(\mathrm{N}=1210)$ was used to test the proposed conceptual model for believers. Table 1 summarized the demographic characteristics of the combined sample and the sub-samples.

\subsection{The Second Sample (The UK Sample $N=178$ )}

\section{Procedures}

Participants were recruited using two strategies. The first was using a crowdsourcing website "prolific.ac", where the participants received $£ 2$ for completing the survey. We specified in the settings that they have to be students or collegeeducated age range 18 - 40, and nationality, country of birth, and country of residence: UK. Further, the link to the online survey was sent to students' university organizations in London.

\section{Participants}

Participants $(\mathrm{N}=178)$, included $60.7 \%$ females. Age ranged between 18 and $40, \mathrm{M}=25.89$, and $\mathrm{SD}=5.66$. Among them, $48.9 \%$ were college students, $39.3 \%$ were employees, $6.2 \%$ were professionals, and $5.6 \%$ were others. Among them, $14.6 \%$ were married, $74.2 \%$ were single, $1.7 \%$ were divorced, and $9.6 \%$ had other marital statuses. For socioeconomic status, $7.3 \%$ reported to have a high income,

Table 1. The demographics of the combined sample and the Egyptian, Turkish and Kuwaiti sub-samples.

\begin{tabular}{|c|c|c|c|c|}
\hline Demographics & Total sample $(\mathrm{N}=1210)$ & Egyptian subsample $(\mathrm{N}=490)$ & $\begin{array}{l}\text { Turkey subsample } \\
\qquad \mathrm{N}=420\end{array}$ & $\begin{array}{l}\text { Kuwaiti subsample } \\
\qquad(\mathrm{N}=300)\end{array}$ \\
\hline Gender & $59.5 \%$ females & $41.4 \%$ females & $27.6 \%$ females & $61 \%$ females \\
\hline Age range & $14-75$ & $14-75$ & $15-65$ & $15-50$ \\
\hline Age Mean (SD) & $\mathrm{M}=26.12(\mathrm{SD}=9.40)$ & $M=26.03(S D=10.90)$ & $\mathrm{M}=23.20,(\mathrm{SD}=8.68)$ & $\mathrm{M}=26.37,(\mathrm{SD}=8.50)$ \\
\hline Adolescents\% & $24.8 \%$ adolescents $(14-19)$ & $20.4 \%$ & $18.4 \%$ & $18.7 \%$ \\
\hline Religion & 68.6\%Muslims, $31.4 \%$ Christians & 49.6\% Muslims, 50.4\% Christians & $94.7 \%$ Muslims $5.3 \%$ others & $\begin{array}{l}\text { 99.7\% Muslims, .3\% } \\
\text { Christians }\end{array}$ \\
\hline Work & $\begin{array}{l}21.5 \% \text { employees, } 1.9 \% \text { workers, } \\
1.5 \% \text { merchants, } 2.7 \% \\
\text { professionals, } 2.4 \% \text { retirees, } \\
61 \% \text { students, } 9 \% \text { other }\end{array}$ & $\begin{array}{l}12.9 \% \text { employees, } 3.1 \% \text { workers, } \\
2.4 \% \text { merchants, } 3.4 \% \text { professionals, } \\
64.5 \% \text { students, } 13.6 \% \text { other }\end{array}$ & $\begin{array}{l}9.7 \% \text { employees, } .9 \% \text { workers, } \\
1.9 \% \text { merchants, } 9.9 \% \\
\text { professionals, } 75.1 \% \text { students, } \\
2.5 \% \text { other }\end{array}$ & $\begin{array}{l}36.7 \% \text { employees, } 55.3 \% \\
\text { students, } 1.3 \% \\
\text { professionals, } 3.7 \% \\
\text { others }\end{array}$ \\
\hline Education & $\begin{array}{l}7.7 \% \text { illiterate or elementary, } 3 \% \\
\text { Middle school, } 22 \% \text { high school, } \\
59.7 \% \text { college, } 7.6 \% \text { graduate } \\
\text { studies }\end{array}$ & $\begin{array}{l}6.1 \% \text { illiterate, } 3.6 \% \text { either } \\
\text { elementary or intermediate, } 27.3 \% \\
\text { high school, } 51.8 \% \text { college, } 11 \% \\
\text { graduate studies. }\end{array}$ & $\begin{array}{l}.5 \% \text { illiterate, } 8.3 \% \text { either } \\
\text { elementary or intermediate, } \\
17.5 \% \text { high school, } 71.7 \% \\
\text { college, } 1.9 \% \text { graduate studies. }\end{array}$ & $\begin{array}{l}4.7 \% \text { elementary school, } \\
20.6 \% \text { high school, } \\
72.7 \% \text { college and } 2 \% \\
\text { graduate students. }\end{array}$ \\
\hline Marital Status & $\begin{array}{l}31 \% \text { married, } 65 \% \text { single, } 1.5 \% \\
\text { widow/widower, } 1.4 \% \\
\text { divorced, } .5 \% \text { other }\end{array}$ & $\begin{array}{l}28.6 \% \text { married, } 68.8 \% \text { singles, } \\
2.6 \% \text { other }\end{array}$ & $\begin{array}{l}15.5 \% \text { were married, } 82.6 \% \\
\text { were single and } 1.9 \% \text { other } \\
\text { marital statuses }\end{array}$ & $\begin{array}{l}35 \% \text { married, } 60.3 \% \\
\text { singles, } 3 \% \text { divorced, } \\
\text { and } 1.7 \% \text { other }\end{array}$ \\
\hline $\begin{array}{l}\text { Socioeconomic } \\
\text { status (SES) }\end{array}$ & $\begin{array}{l}2,1 \% \text { very low or low, } \\
75.8 \% \text { middle, } 18.2 \% \text { high, } \\
3.8 \% \text { very high }\end{array}$ & $\begin{array}{l}3 \% \text { very low or low, } 75.1 \% \\
\text { middle, } 21.9 \% \text { high or very high }\end{array}$ & $\begin{array}{l}.5 \% \text { very low, } 6.5 \% \text { low, } 84.8 \% \\
\text { middle, } 6.5 \% \text { high, } 1.7 \% \text { very } \\
\text { high }\end{array}$ & $\begin{array}{l}.0 \% \text { very low, } 0.7 \% \text { low, } \\
77 \% \text { middle, } 22.3 \% \text { high } \\
\text { or very high, }\end{array}$ \\
\hline
\end{tabular}


$70.2 \%$ reported to have enough income, $20.8 \%$ reported to be poor, and $1.7 \%$ reported to be very poor. For religion, participants included $24.2 \%$ Christians, .6\% Jewish, $4.5 \%$ other religions, while $70.8 \%$ with no religious affiliation (non-religious). For education, $21.3 \%$ had a high school, $57.3 \%$ had an undergraduate degree, and $21.3 \%$ had a postgraduate degree.

\section{Measures (the same measures were used in the two samples): \\ Translation of the measures to Arabic and Turkish}

For the Arabic version of the measures, all measures were previously translated into Arabic using the scientific procedures of translation and back-translation and were validated and utilized in research projects in different Arabic populations. For the Turkish language, the measures were translated and back-translated by professionals who were fluent in both languages (English and Turkish). They were tested on a focus group of 10 graduate students who gave feedback on the final versions. The cumulative trauma scale was validated in a separate study on Turkish populations (Eltan, 2019).

\section{Predictor Variables Measures}

Interfaith Spirituality Scale (23 items), (Kira et al., 2019c): IFS included 25 items that represented five components (and subscales): direct connection with the creating force, asceticism, unity of existence, meditation, and divine love. Because the unity of existence subscale had low reliability, it was eliminated from analysis. For each item, each participant was asked to indicate to what extent each statement is true for him/her on a scale from 1 - 4, with (4) Mostly true about me, and (1) Not true about me. The instruction introduced a specific definition of spirituality as "the feeling of a direct relationship with your creator, and your ability to transcend yourself. With "Creator" means the power that put everything into existence, as you perceive it." Exploratory and confirmatory factor analysis validated its structure and found a second-order unitary construct of IFS. The measure was found to be strictly invariant across religions, genders, ages, and regional groups. IFS and its subscales were associated with religiosity, higher self-esteem, higher emotional regulation, higher will to exist live and survive, and posttraumatic growth. They were negatively associated with PTSD, depression, suicidality, externalizing, thought disorder, and psychopathology in general. Internal consistency a for the scale (23 items) was .92. Test-retest (4 weeks interval between time 1 and time 2$)$ on a sample of $(\mathrm{N}=34)$ found to be .72 .

The "will to exist, live and survive (WTELS)" scale (Kira et al., 2020b; Kira, et al., 2020e). WTELS scale is a 6-item scale that measures different aspects of will to exist, live, survive, and thrive. It includes items such as "I am motivated by a drive to live"; "My will to exist and survive adversity is generally high." We scored each item on a 5 -point scale: $4=$ very strong, $3=$ strong, $2=$ neutral, $1=$ drained/depleted, $0=$ extremely depleted/I have no will to survive. Exploratory and confirmatory factor analyses found that the measure has a one-factor structure. The measure's one-factor structure was strictly invariant across gender, 
cultural, and religious groups. We should clarify that the WTELS scale is a short parsimonious measure, which did not allow robust testing of its three distinct unique components structure. WTELS construct is comprised of three distinct but overlapping components. A three-factor model was not established or tested because it was a short instrument consisting of only six items (a longer test allows at least four items per dimension).

Additionally, the study found that the measure's test-retest stability coefficient (4 weeks interval) on a sample $(\mathrm{N}=34)$ to be .82 . WTELS has good convergent, divergent, and predictive validity. WTELS predicted a decrease in existential anxiety, mental health symptoms, and an increase in emotion regulation (reappraisal), self-esteem, and posttraumatic growth (Kira et al., 2020e). The Cronbach's reliability of the scale in current data is .89.)

Cumulative Stressors and Traumas Scale (CST-Short version) (Kira et al., 2008a) The Cumulative Stressors and Traumas Scale CST-S (short form) is a measure that was constructed based on the development-based trauma framework (DBTF) e.g., (Kira, 2001; Kira, 2021; Kira et al., 2013a; Kira et al., 2013b; Kira et al., 2008a; Kira et al., 2018a; Kira et al., 2020a). DBTF identifies different dimensions of individual development that may be affected by stressors and traumatic stressors (i.e., attachment, personal, collective, and role identities, and interdependence, as well as serious non-acute stressors). The CTS-S is a 32-item instrument that measures cumulative stressors and traumas and trauma types in terms of occurrence, frequency, and negative and positive appraisals. The scale is intended to be a comprehensive measure of cumulative stressors and traumatic exposures. Cumulative non-traumatic stressors included the serious life changes associated with widowed/divorce and re-marrying, as well as the major life changes in forced relocations (e.g., uprootedness and immigration), and the experience of seemingly small but recurrent or unremitting hassles or chronic stressors. The scale includes, in addition to cumulative non-traumatic stressors (3 items), seven major trauma types (acute stressors): collective identity trauma ( 3 items), personal identity trauma (6 items), survival trauma (6 items), attachment trauma (2 items), secondary trauma (7 items), achievement traumas (2 items) and gender discrimination ( 2 items). Recently, the scale developers added three items that measure: perpetration trauma, community violence, and birthing trauma (complicated birth) as optional items for interested researchers. Collective identity trauma includes trauma-related to exposure to war and torture and discrimination based on race, ethnicity, or national origin. Personal identity trauma includes trauma related to sexual abuse, rape, incest, and being robbed. Attachment trauma includes abandonment by parents. Survival trauma includes car accidents, life-threatening illnesses, and natural disasters. Achievement or role identity trauma is intended to measure traumatic stressors related to the achievement of life goals like success in school or business. Secondary trauma includes trauma related to having witnessed a traumatic event occurring to another individual or group and affecting social interdependence. Gender discrimination includes gender discrimination by parents (family) and gender dis- 
crimination by society and institutions. Gender discrimination items are worded to apply to both genders. In response to each item on the measure, participants are instructed to indicate their experience with a traumatic event on a 5-point Likert-type scale $(0=$ never; $4=$ many times). If a participant denotes that she/he has experienced the traumatic event, then he/she is asked to describe her/his appraisal of its effect on a 7-point Likert-type scale $(1=$ extremely positive; $7=$ extremely negative). CTS-S includes two general subscales for cumulative trauma dose: occurrence and frequency of experience, and two appraisal subscales: negative and positive appraisal of events. These four sub-scales may be also generated for each of the trauma types.

The CTS-S has shown adequate internal consistency $\alpha=.85$; (Kira et al., 2008a; Kira et al., 2013c). Test-retest using an independent sample of 35 males with four weeks interval yielded excellent stability coefficients ( .995 for cumulative trauma frequency, and .997 for cumulative trauma appraisal). The measure proved to have good predictive validity with cumulative stressors and traumas highly predicted psychopathology and suicidality (Kira et al., 2019a, 2020a). Evidence of the instrument's predictive validity includes cumulative trauma significantly predicting post-traumatic stress disorder $(\mathrm{r}=.54, p<.001)$, cumulative trauma-related disorders $(\mathrm{r}=.24, \mathrm{p}<.001)$, and poor health $\mathrm{r}=.37, p<.001$ (Kira et al., 2008a). CTS-S has also shown divergent validity: It was significantly negatively correlated with sociocultural adjustment $(\mathrm{r}=-.25, p<.001)$ and futuristic orientation $(\mathrm{r}=-.37, p<.001)$. CTS-S has been used with a variety of clinical and community samples of adults and adolescents from numerous sociocultural groups and has been shown to possess adequate reliability (with an alpha ranging between .80 and .92), good construct validity e.g., (Kira et al., 2008a, Kira et al., 2012b; Kira et al., 2010; Kira \& Shuwiekh, 2021; Kira et al., 2020c), and validity across different cultural and clinical groups, including American Indians, Mayans, Palestinians, Egyptians, refugees, and torture survivors from 32 countries e.g., (Kira et al., 2013d; Kira et al., 2013c; Kira et al., 2014c; Kira et al., 2010). The measure has been used in several studies as a comprehensive measure of stress and trauma e.g., (Eltan, 2019; Gillespie \& Gates, 2013; Head et al., 2012; Millender, 2013; Omidy, 2012; Rizeq et al., 2018), and has been found to have good reliability and predictive validity. It has been translated into different languages including Arabic, Spanish, Polish, Korean, and Nigerian, and proved to have good psychometric properties in these languages. The alpha for the main scale of occurrence was .88 in believers and .90 in non-believers.

\section{Mediating Variables Measures}

Existential Annihilation Anxieties measure (EAA) (Kira et al., 2012c; Kira et al., 2020b; Kira et al., 2019b; Kira et al., 2018b). Its original three items version was found to have high reliability, stability, and predictive validity. The extended and refined version included 15 items and was tested in three samples: Egypt, Kuwait, and the UK. In the present study, the measure was found to have an alpha of .89. Factor analysis found four factors (subscales); Psychic EAA related to personal identity trauma, EAA related to collective identity trauma, EAA related 
to social status traumas, and EAA related to fear of physical death. The measure was found to be significantly associated with cumulative trauma, PTSD, depression, thought disorder, internalizing, externalizing and suicidality, poor reported physical health, gender, and other discriminations, and sexual abuse. It was negatively associated with "the will to exist, live and survive", spirituality, religiosity, self-esteem, and emotion-regulation (Kira \& Shuwiekh, 2021).

The Rosenberg self-esteem scale (RSES) is a 10-item scale that measures global self-esteem (Rosenberg, 2015). Each item rated on a 4-point Likert-type scale with a range from strongly agrees to disagree strongly and scored from 0 to 3 . The scale is divided into five positively worded and five negatively worded statements. The RSES has been translated and adapted to various languages including Arabic. Rosenberg reported good psychometrics for the scale and its reliability ranging from .85 to .88 . In a previous Arabic sample, the alpha was .75. Testretest using an independent sample of 35 males with four weeks interval yielded a stability coefficient of .983. Its alpha reliability was .744 in the current study.

Emotion Regulation Questionnaire (ERQ) (Gross \& John, 2003) comprises ten items assessing the reappraisal (6 items) and suppression (4 items). The questionnaire measures two emotion regulation strategies: reappraisal and suppression. An example of the items of reappraisal subscale is: (I control my emotions by changing the way I think about the situation I am in). An example of items of suppression subscale is: (I control my emotions by not expressing them). Items are rated on a 7-point Likert-type response scale. Higher scores on each scale indicate greater use of the corresponding ER strategy. The ERQ has been reported to have adequate internal consistency ( $\alpha=.79$ for Reappraisal, and .73 for Suppression) and 3-month test-retest reliability ( $\mathrm{r}=.69$ for both scales), as well as sound convergent and discriminant validity with both younger and older adults (Gross \& John, 2003; John \& Gross, 2004). The measure was previously scientifically translated into Arabic and found to have good psychometrics. In the current data, reappraisal has $(\alpha=.89)$, and suppression has $(\alpha=.78)$.

The religiosity scale is five items that had been used previously in similar populations e.g., (Al-Ibraheem et al., 2017). It contains items that measure the consistent practice of religion. It includes also items about congregating with persons from the same religion, reading the religion's Holy Book, and giving to religious charities. The measure had $\alpha=.70$ in the present study.

Outcome or Dependent Variables Measures

Clinician-administered PTSD Scale CAPS-2 PTSD Measure (CAPS-2) (18 items). This scale was developed by (Blake et al., 1995). It is widely used to assess PTSD symptoms (DSM IV version). It is a structured clinical interview that evaluates 17 symptoms rated on frequency and severity on a 5-point scale. CAPS demonstrated high reliability with a range between .92 - .99 and showed good convergent and discriminant validity (Weathers et al., 2001). In this study, we used the frequency subscale of CAPS-2 that is currently widely used in the psychiatric literature and is highly correlated with the total scale. The scale in the 
current study has high reliability with an alpha of .97 .

Psychopathology Screening measure (Kira et al., 2017) reconstructed GAIN Short Screener (GAIN-SS) (Dennis et al., 2006) is a 20 items scale that measures the three factors of psychopathology: internalizing, externalizing, and or thought disorders e.g., (Caspi et al., 2014; Laceulle et al., 2015). The participant is asked to indicate if the behavior (or feeling) happened in the past month (scored 4), or happened in the last 2-3 months (scored 3), or in the last 3 - 12 months (scored 2 ), or the last year or more (scored 1), or never happened (scored 0 ). High scores indicate potentially higher symptoms in these areas. Exploratory and Confirmatory Factor Analysis of the adapted measure in different data in Egypt and Poland yielded three factors: Internalizing, Externalizing, and psychoticism. Testretest using an independent sample of 35 males with four weeks interval yielded excellent stability coefficients (.97 for internalizing, .91 for externalizing, 92 for the combined externalizing and addiction subscale. In the current study, alpha reliability for internalizing was $.84, .88$ for externalizing and addiction, and .93 for psychoticism. The total psychopathology scale had an alpha of .89 in current data.

Depression Single item measure (Chochinov et al., 1997): This single-item measure for depression was found to correctly identify eventual diagnostic outcome of every patient, outperforming questionnaire and visual analog measures.

The Post-Traumatic Growth Inventory (PTGI); (Tedeschi \& Calhoun, 1996) assesses perceived positive life changes (e.g., enhanced relationships, greater life appreciation) following stressful experiences. The participant was asked to indicate for each of the statements the degree to which this change occurred in her/his life as a result of potential crises that may have happened due to the various adversities that he/she may have ever encountered. That was the standard question. However, for torture survivors, when we researched populations that have higher rates of torture survivors, (e.g., Syrians) we specified, asking if this crisis may happen due to torture and all the other adversities that he/she may have ever encountered. In completing the 21 items, participants respond on a scale from 0 (I did not experience this change as a result of my experience) to 5 (I experienced this change to a very significant degree). The measure includes five subscales: relating to others, new possibilities, personal strength, spiritual change, and appreciation of life. In a validation study, (Tedeschi \& Calhoun, 1996) found the internal consistency (alpha) of the total PTGI to be .90 and the test-retest reliability coefficient to be .71 . The measure also appears to have sound psychometric properties in the Arabic language version (Kira et al., 2012a; Kira et al., 2013a), with an alpha of .96 for the main measure. In the current data, the scale had an alpha of .90. Alpha coefficients ranged between .83 and .70 for its five subscales.

\section{Statistical Analysis}

The data were analyzed utilizing IBM-SPSS 22, as well as Amos 22 software. We 
compared the two samples in the main variables using an independent sample T-test. We conducted a zero-order correlation between the primary variables in each sample. We explored the differences between gender, age, regional and religious groups in Spirituality using the independent sample t-test and one wayANOVA.

We conducted a path analysis to test the proposed conceptual model fit in each sample. The Path model included cumulative stress and traumas, Spirituality and will to live as independent variables and reappraisal, suppression (emotion regulation), and self-esteem as mediators/moderators variables, and PTSD and perceived PTG as outcome variables. We will report direct, indirect, and total effects as standardized regression coefficients. Following (Byrne, 2012)'s recommendations, the criteria for good model fit were a non-significant $\left(\chi^{2}\right)$, $\left(\chi^{2} /\right.$ d.f. $\left.>2\right)$, comparative fit index (CFI) values $>.90$, and root-meansquare error of approximation (RMSEA) values $<.06$. We used a bootstrapping procedure with 10,000 bootstrap samples to examine the significance of direct, indirect (mediated effects), and total effects and 95\% bias-corrected confidence intervals $(95 \% \mathrm{CI})$ for each variable in the model. To simplify the presentation, we trimmed the model by eliminating the non-significant paths.

We supplemented path analysis by SPSS PROCESS macro (Hayes, 2013). PROCESS, while analyzing only one independent and one dependent variable at a time, can identify the mediators of the indirect effects and their effect sizes. We used PROCESS macro: model 4, to test the spirituality and WTELS direct effects and indirect effects through multiple mediators and their relative strength (effect size and confidence intervals). We controlled for age, gender, and the group as covariates. We used bootstrapping sampling $(\mathrm{n}=5000)$ distributions to calculate the direct and indirect effects and confidence intervals (95\%) of the estimated effects. The point estimate is considered significant when the confidence interval does not contain zero.

Additionally, for the first sample, to assess whether the structural path model is invariant across genders, religious affiliations (Christian and Muslims), and regions (Upper Egypt, Middle Egypt, and Cairo, Kuwait), we conducted multi-group invariance analysis (Sarstedt et al., 2011). Four nested models were tested sequentially: a configural invariance model, a metric invariance model, a scalar invariance model, and a strict invariance model e.g., (van de Schoot et al., 2012). Although there is broad acceptance of the steps for testing measurement invariance, the criteria for evaluating the invariance of the models at each level are not as clear. Chi-square tests LRT is highly sensitive to sample size e.g., (Meade \& Lautenschlager, 2004), potentially leading to an excessively conservative test of invariance and is controversial to be used with large samples. (Byrne et al., 1989), have argued that invariance can be established when two indicators are invariant. According to (Chen, 2007), the null hypothesis of invariance should not be rejected when changes in CFI are less than or equal to .01 and in 
RMSEA are less than or equal to 0.015 .

\section{Results}

\subsection{The Differences between the Two Samples}

The participants in the first sample (mostly believers), as expected, are much higher in spirituality $(t=38.13)$ and religiosity $(t=23.25)$, and collective identity salience $(t=19.16)$. However, the participants in the second sample (mostly non-believer) have significantly higher "will to exist live and survive". The participants in the second sample who were mostly non-believers have higher cumulative stressors and traumas and consequently have higher internalizing, externalizing, and thought disorders and poor physical health, as well as lower, perceived PTG. There are no significant differences in emotional regulation strategies of reappraisal or suppression between them. Table 2 presents the details of these results.

\subsection{Correlational Results for the First Sample}

The interfaith spirituality (IFS) scale was significantly correlated with religiosity, self-esteem, emotion regulation strategies of reappraisal and suppression, will to exist/live and survive, and perceived PTG. It was negatively significantly correlated with psychopathology, and existential anxieties (see Table 3). To be more specific, IFS and all its subscales were associated with religiosity. IFS and its subscales were associated with decreased internalizing except for the "meditation" subscale. IFS and its subscales were associated with decreased externalizing, suicidality, psychopathology, EAA, and thought disorder. They were positively associated with "will to exist, live, and survive" "self-esteem," "reappraisal," "suppression" and "perceived PTG" (see Table 4).

Table 2. T-test for the differences between the two samples in the main variables.

\begin{tabular}{|c|c|c|c|c|c|c|c|}
\hline \multirow[t]{2}{*}{ variable } & \multicolumn{2}{|c|}{$\begin{array}{l}\text { The first sample } \\
\text { (Mostly Believers) }\end{array}$} & \multicolumn{2}{|c|}{$\begin{array}{l}\text { The second sample } \\
\text { (Mostly Non-Believers) }\end{array}$} & \multirow[b]{2}{*}{$t$} & \multirow[b]{2}{*}{$d f$} & \multirow[b]{2}{*}{$p$} \\
\hline & $M$ & $S D$ & $M$ & $S D$ & & & \\
\hline IFS & 82.16 & 14.20 & 37.31 & 17.17 & 38.13 & 1385 & .000 \\
\hline Religiosity & 15.45 & 3.45 & 8.80 & 3.96 & 23.25 & 1385 & .000 \\
\hline WTELS & 21.07 & 4.63 & 22.83 & 4.60 & -4.73 & 1385 & .000 \\
\hline C. Identity Salience & 31.54 & 14.15 & 10.90 & 5.93 & 19.16 & 1385 & .000 \\
\hline CST & 3.39 & 3.08 & 7.32 & 8.01 & -12.07 & 1385 & .000 \\
\hline Reappraisal & 28.26 & 7.54 & 28.57 & 6.80 & -.53 & 1385 & .600 \\
\hline Suppression & 16.91 & 5.38 & 16.76 & 5.28 & .35 & 1385 & .724 \\
\hline PTG & 52.32 & 23.40 & 46.05 & 23.08 & 3.34 & 1385 & .001 \\
\hline
\end{tabular}




\section{Continued}

\begin{tabular}{cccccccc}
\hline Internalizing & 11.64 & 7.02 & 23.44 & 8.34 & -20.39 & 1385 & .000 \\
Externalizing & 2.80 & 4.80 & 13.77 & 6.56 & -26.97 & 1385 & .000 \\
Thought Disorders & 7.45 & 6.80 & 14.72 & 7.91 & -13.01 & 1385 & .000 \\
Poor Health & 5.98 & 3.14 & 8.93 & 3.71 & -11.39 & 1385 & .000 \\
\hline
\end{tabular}

Note: IFS = Interfaith Spirituality, WTELS = "wil to exist live and survive", C. Identity Salience = collective identity salience, $\mathrm{CST}=$ Cumulative stressors, and traumas.

Table 3. Zero order correlations between spirituality and selected variables in the combined first sample $(\mathrm{N}=1210)$.

\begin{tabular}{lcccccccc}
\hline \multicolumn{1}{c}{ Variables } & 1 & 2 & 3 & 4 & 5 & 6 & 7 & 8 \\
\hline 1. Spirituality & 1 & & & & & & & \\
2. Self-esteem & $.31^{* * *}$ & 1 & & & & & & \\
3. PTG & $.16^{* * *}$ & $.12^{* * *}$ & 1 & & & & & \\
4. Suppression & $.14^{* * *}$ & -.03 & $.10^{* *}$ & 1 & & & & \\
5. Reappraisal & $.22^{* * *}$ & $.20^{* * *}$ & $.18^{* * *}$ & $.45^{* * *}$ & 1 & & & \\
6. EAA & $-.23^{* * *}$ & $-.43^{* * *}$ & .04 & -.04 & $-.20^{* * *}$ & 1 & & \\
7. WTELS & $.18^{* * *}$ & $.44^{* * *}$ & $.14^{* * *}$ & -.01 & $.24^{* * *}$ & $-.31^{* * *}$ & 1 & \\
8. Religiosity & $.26^{* * *}$ & $.25^{* * *}$ & .04 & .03 & $.20^{* * *}$ & $-.24^{* * *}$ & $.29^{* * *}$ & 1 \\
\hline
\end{tabular}

Note: ${ }^{*} p<.05,{ }^{* *} p<.01,{ }^{* * *} p<.001$.

Table 4. Zero-order correlations between spirituality and its components and selected variables in the first sample $(\mathrm{N}=1210)$.

\begin{tabular}{cccccc}
\hline Variables & IFS Scale & $\begin{array}{c}\text { Direct connection } \\
\text { with the Creator }\end{array}$ & Asceticism & Meditation & Divine love \\
\hline Religiosity & $.26^{* * *}$ & $.24^{* * *}$ & $.25^{* * *}$ & .04 & $.18^{* * *}$ \\
Internalizing & $-.14^{* * *}$ & $-.13^{* * *}$ & $-.17^{* * *}$ & -.03 & $-.13^{* * *}$ \\
Externalizing & $-.21^{* * *}$ & $-.27^{* * *}$ & $-.16^{* * *}$ & $-.07+$ & $-.30^{* * *}$ \\
Thought Disorder & $-.20^{* * *}$ & $-.20^{* * *}$ & $-.20^{* * *}$ & $-.08^{*}$ & $-.17^{* * *}$ \\
Suicidality & $-.18^{* * *}$ & $-.17^{* * *}$ & $-.18^{* * *}$ & -.06 & $-.24^{* * *}$ \\
Psychopathology & $-.23^{* * *}$ & $-.25^{* * *}$ & $-.23^{* * *}$ & $-.08^{*}$ & $-.25^{* * *}$ \\
Depression & $-.17^{* * *}$ & $-.17^{* * *}$ & $-.15^{* * *}$ & -.01 & $-.12^{* * *}$ \\
WTELS & $.18^{* * *}$ & $.18^{* * *}$ & $.20^{* * *}$ & .03 & $.16^{* * *}$ \\
EAA & $-.23^{* * *}$ & $-.27^{* * *}$ & $-.20^{* * *}$ & $-.07+$ & $-.20^{* * *}$ \\
Reappraisal & $.22^{* * *}$ & $.19^{* * *}$ & $.21^{* * *}$ & $.13^{* * *}$ & $.21^{* * *}$ \\
Suppression & $.14^{* * *}$ & $.09^{* *}$ & $.09^{*}$ & $.16^{* * *}$ & $.12^{* * *}$ \\
PTG & $.16^{* * *}$ & $.13^{* * *}$ & $.10^{* *}$ & $.19^{* *}$ & $.14^{* * *}$ \\
Self-esteem & $.31^{* * *}$ & $.33^{* * *}$ & $.27^{* * *}$ & $.14^{* * *}$ & $.27^{* * *}$ \\
\hline
\end{tabular}

\subsection{Path Analysis and PROCESS Mediation Results for the First Sample}

Interfaith spirituality had direct negative effects on existential annihilation anxiety (EAA) and direct positive effects on perceived posttraumatic growth (PTG). 
It had direct and indirect negative effects on psychopathology, and direct and indirect positive effects on self-esteem, reappraisal, and suppression. According to PROCESS mediation analysis, self-esteem (effect $=-.06$. se $=.02, \mathrm{Z}=-3.62, p$ $=.000$, Bout LLCI $=-.10$, and Bout ULCI $=-.03$ ), will to exist, live and survive (WTELS) (effect $=-.02 . \mathrm{se}=.01, \mathrm{Z}=-2.27, p=.02$, Bout LLCI $=-.04$, Bout $\mathrm{ULCI}=-.01$ ), and reappraisal (effect $=-.02 . \mathrm{se}=.01, \mathrm{Z}=-2.06, p=.04$, Bout LLCI $=-.05$, Bout ULCI $=-.00)$, mediated interfaith spirituality negative indirect effects on psychopathology.

WTELS had direct negative effects on EAA, direct and indirect negative effects on Psychopathology. Its indirect negative effect on psychopathology were mediated by self-esteem (effect $=-.20$. se $=.05, \mathrm{Z}=-3.72, p=.000$, Bout LLCI $=$ -.32 , and Bout ULCI $=-.11$ ), Spirituality (effect $=-.08$. se $=.03, \mathrm{Z}=-2.84, p$ $=.004$, Bout LLCI $=-.15$, and Bout ULCI $=-.04)$, and reappraisal $($ effect $=-.06$. $\mathrm{se}=.03, \mathrm{Z}=-2.08, p=.039$, Bout LLCI $=-.12$, and Bout ULCI $=-.01)$. WTELS had direct and indirect positive effects on self-esteem, PTG, and reappraisal. Its indirect effects on self-esteem were mediated by spirituality (effect $=.05$, se $=.01, \mathrm{Z}=3.43, p=.001$, bout LLCI $=.03$, and Bout ULCI $=.08$ ), and reappraisal (effect $=.02$, se $=.01, \mathrm{Z}=2.20, p=.028$, bout LLCI $=.01$, and Bout ULCI $=.05$ ). Its indirect effects on perceived PTG were mediated by reappraisal (effect $=.17$, $\mathrm{se}=.06, \mathrm{Z}=2.69, p=.007$, Bout LLCI $=.07$, and Bout ULCI $=.30$ ), and spirituality (effect $=.11$, se $=.04, \mathrm{Z}=2.30, p=.022$, Bout LLCI $=.04$, and Bout ULCI $=.23$ ). Its indirect positive effects on reappraisal were mediated by self-esteem (effect $=.06$, se $=.02, \mathrm{Z}=2.36, p=.018$, Bout LLCI $=.01$, and Bout ULCI $=.11$ ), PTG (effect $=.04$, se $=.01, \mathrm{Z}=2.64, p=.007$, Bout LLCI $=.02$, and Bout ULCI $=.07$ ), and spirituality (effect $=.03$, se $=.01, \mathrm{Z}=2.10, p=.036$, Bout LLCI $=.01$, and Bout ULCI $=.06$ ).

Cumulative trauma's positive effects on EAA were totally direct. Cumulative trauma had indirect positive effects on psychopathology and indirect negative effects on self-esteem. Its indirect negative effects on psychopathology were strongly mediated by EAA (effect $=.48$, se $=.09, \mathrm{Z}=4.997, p=.000$, Bout LLCI $=.30$, and Bout ULCI $=.66)$. Its indirect negative effects on self-esteem were mediated by EAA (effect $=-.12$, se $=.02, \mathrm{Z}=-4.70, p=.000$, Bout LLCI $=-.17$, and Bout ULCI $=-.07)$. Cumulative trauma had direct positive effects on reappraisal, suppression, and perceived PTG.

EAA had strong positive direct effects on Psychopathology and direct negative effects on self-esteem and reappraisal. It has indirect positive effects on perceived PTG. Its positive effects on perceived PTG were mediated by the cumulative trauma (effect $=.11$, se $=.03, \mathrm{Z}=4.004, p=.000$, Bout LLCI $=.07$, and Bout $\mathrm{ULCI}=.17$ ). Adversities and existential anxieties seem to have the potential of promoting PTG. Psychopathology had direct positive effects on perceived PTG. Self-esteem had direct negative effects on suppression. Reappraisal had direct positive effects on perceived PTG and reappraisal. Table 5 includes the direct, indirect, and total effects of each variable and its $95 \%$ confidence intervals. Figure 2 illustrates the direct effects of each variable. 
Table 5. Path analysis direct, indirect, and total effects of interfaith spirituality, WTELS, cumulative trauma, and EAA on the other variables and their $95 \%$ confidence intervals in the first sample $(\mathrm{N}=1210)$.

\begin{tabular}{|c|c|c|c|c|c|c|}
\hline \multirow{2}{*}{ Causal Variables } & \multicolumn{6}{|c|}{ Endogenous Variables } \\
\hline & EAA & Psychopathology. & Self-esteem & Reappraisal & PTG & Suppress. \\
\hline \multicolumn{7}{|c|}{ Interfaith Spirituality } \\
\hline Direct Effects & $\begin{array}{c}-.17^{\star *} \\
(-.25 /-.11)\end{array}$ & $\begin{array}{c}-.09^{* *} \\
(-.16 /-.04)\end{array}$ & $\begin{array}{c}.19^{\star *} \\
(.13 / .26)\end{array}$ & $\begin{array}{l}.16^{* * *} \\
(.10 / .25)\end{array}$ & $\begin{array}{c}.15^{* *} \\
(.07 / .22)\end{array}$ & $\begin{array}{c}.09^{* *} \\
(.02 / .14)\end{array}$ \\
\hline Indirect Effects & & $\begin{array}{c}-.09^{* *} \\
(-.13 /-.06)\end{array}$ & $\begin{array}{c}.05^{\star *} \\
(.03 / .07)\end{array}$ & $\begin{array}{l}.03^{\star * *} \\
(.01 / .04)\end{array}$ & $\begin{array}{c}-.00 \\
(-.03 / .02)\end{array}$ & $\begin{array}{c}.05^{\star * *} \\
(.02 / .09)\end{array}$ \\
\hline Total Effects & $\begin{array}{c}-.17^{\star *} \\
(-.25 /-.11)\end{array}$ & $\begin{array}{c}-.18^{\star *} \\
(-.26 /-.12)\end{array}$ & $\begin{array}{c}.24^{\star \star} \\
(.17 / .31)\end{array}$ & $\begin{array}{c}.19^{* * *} \\
(.12 / .27)\end{array}$ & $\begin{array}{c}.15^{\star \star} \\
(.07 / .22)\end{array}$ & $\begin{array}{c}.14^{\star \star} \\
(.07 / .20)\end{array}$ \\
\hline \multicolumn{7}{|l|}{ WTELS } \\
\hline Direct Effects & $\begin{array}{c}-.27^{\star \star} \\
(-.33 /-.21)\end{array}$ & $\begin{array}{c}-.09^{\star} \\
(-.15 /-.03)\end{array}$ & $\begin{array}{c}.31^{\star *} \\
(.25 / .38)\end{array}$ & $\begin{array}{c}.18^{\star *} \\
(.11 / .25)\end{array}$ & $\begin{array}{c}.14^{\star * *} \\
(.08 / .24)\end{array}$ & \\
\hline Indirect Effects & & $\begin{array}{c}-.14^{* * *} \\
(-.18 /-.11)\end{array}$ & $\begin{array}{c}.08^{* *} \\
(.05 / .10)\end{array}$ & $\begin{array}{l}.03^{* * *} \\
(.02 / .06)\end{array}$ & $\begin{array}{c}-.01 \\
(-.04 / .01)\end{array}$ & $\begin{array}{c}.04 \\
(-.00 / .08)\end{array}$ \\
\hline Total Effects & $\begin{array}{c}-.27^{\star *} \\
(-.33 /-.21)\end{array}$ & $\begin{array}{c}-.23^{\star *} \\
(-.29 /-.17)\end{array}$ & $\begin{array}{c}.39^{\star *} \\
(.33 / .45)\end{array}$ & $\begin{array}{c}.21^{\star * *} \\
(.16 / .29)\end{array}$ & $\begin{array}{c}.13^{\star *} \\
(.08 / .23)\end{array}$ & $\begin{array}{c}.04 \\
(-.00 / .08)\end{array}$ \\
\hline
\end{tabular}

\section{Cumulative Trauma}

\begin{tabular}{|c|c|c|c|c|c|c|}
\hline Direct Effects & $\begin{array}{c}.08^{\star} \\
(.01 / .16)\end{array}$ & & & $\begin{array}{c}.13^{\star *} \\
(.07 / .19)\end{array}$ & $\begin{array}{c}.16^{\star *} \\
(.09 / .22)\end{array}$ & \\
\hline direct $\mathrm{Ef}$ & & $\begin{array}{c}.04^{\star} \\
(.01 / .09)\end{array}$ & $\begin{array}{c}-.02^{\star} \\
(-.05 /-.00)\end{array}$ & $\begin{array}{c}-.01^{* *} \\
(-.02 /-.00)\end{array}$ & $\begin{array}{c}.02^{\star *} \\
(.01 / .04)\end{array}$ & $\begin{array}{c}.06^{* *} \\
(.04 / .09)\end{array}$ \\
\hline Total Effects & $\begin{array}{c}.08^{\star} \\
(.01 / .16)\end{array}$ & $\begin{array}{c}.04^{*} \\
(.01 / .09)\end{array}$ & $\begin{array}{c}-.02^{\star} \\
(-.05 /-.00)\end{array}$ & $\begin{array}{c}.12^{* *} \\
(.06 / .19)\end{array}$ & $\begin{array}{c}.18^{*} \\
(.11 / .24)\end{array}$ & $\begin{array}{c}.06^{* *} \\
(.04 / .09)\end{array}$ \\
\hline
\end{tabular}

EAA

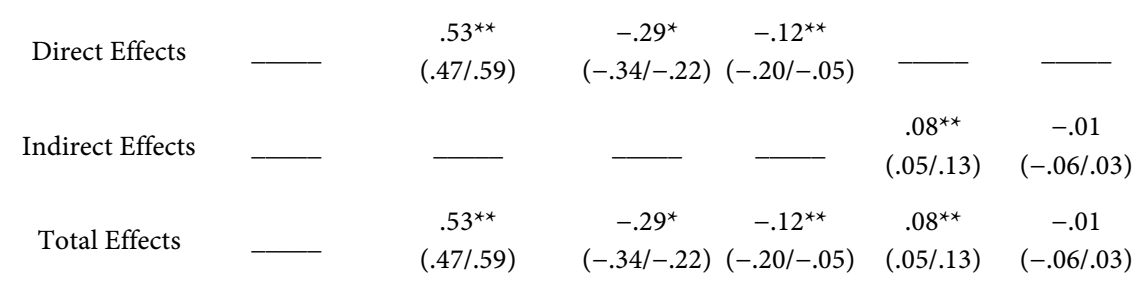

\section{Psychopathology}

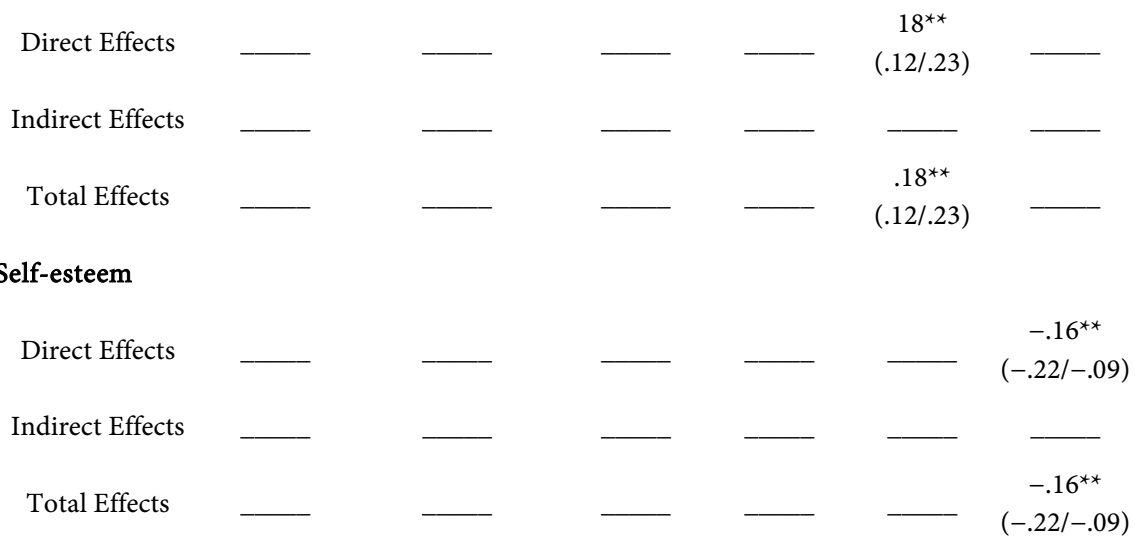




\section{Continued}

\begin{tabular}{|c|c|c|c|c|c|c|}
\hline \multicolumn{7}{|l|}{ Reappraisal } \\
\hline Direct Effects & & & - & & $\begin{array}{c}.13^{* *} \\
(.05 / .22)\end{array}$ & $\begin{array}{c}.46^{* *} \\
(.40 / .53)\end{array}$ \\
\hline Indirect Effects & & & - & 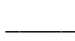 & $\underline{-}$ & 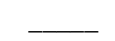 \\
\hline Total Effects & & & & & $\begin{array}{c}.13^{\star *} \\
(.05 / .22)\end{array}$ & $\begin{array}{c}.46^{* *} \\
(.40 / .53)\end{array}$ \\
\hline Squared $\mathrm{R}$ & .129 & .352 & .317 & .116 & .113 & .229 \\
\hline
\end{tabular}

Notes. ${ }^{*} p<.05,{ }^{* *} p<.01,{ }^{* * *} p<.001$

$$
\text { Chi Square = } \begin{gathered}
\mathrm{N}=1210 \\
\mathrm{C} .342, \mathrm{~d} . \mathrm{f} .=12, p=.106 \\
\mathrm{RMSEA}=.995
\end{gathered}
$$

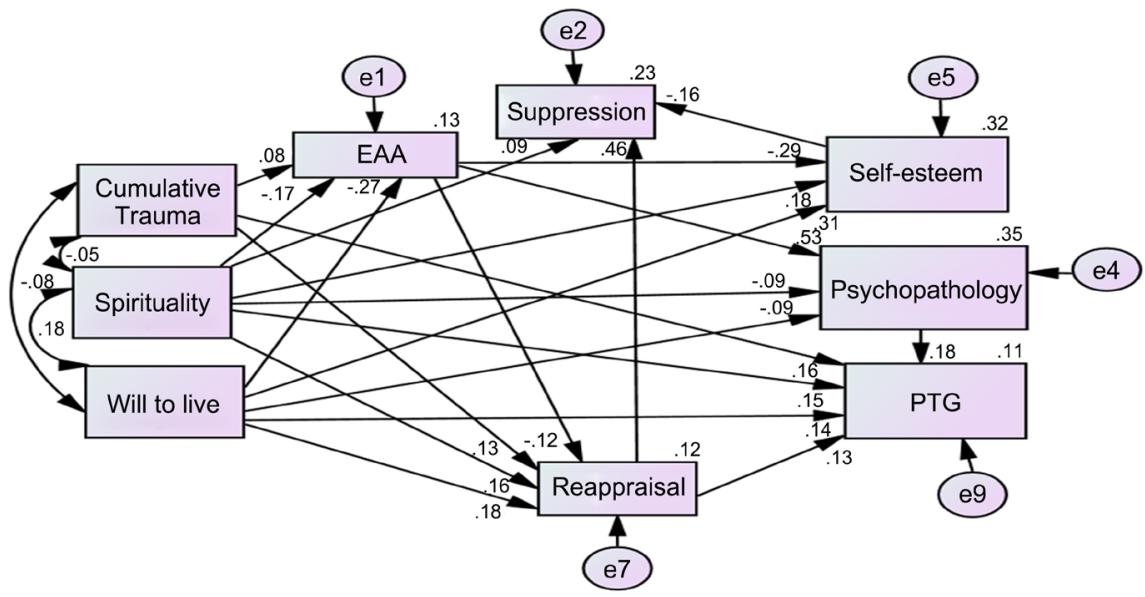

Figure 2. Path diagram for the direct effects of spirituality, WTELS, cumulative trauma, on self-esteem, psychopathology, and PTG, mediated by EAA, emotion regulation (reappraisal and suppression) in the believers' sample $(\mathrm{N}=1210)$.

Figure 2 Path diagram for the direct effects of spirituality, WTELS, cumulative trauma, on self-esteem, psychopathology, and PTG, mediated by EAA, emotion regulation (reappraisal and suppression) in the believers' sample $(\mathrm{N}=1210)$.

\subsection{Structural Invariance of the Path Model in the First Sample}

Multigroup structural invariance indicated that the path model of Spirituality dynamics is strictly invariant across genders, religious groups (Muslims and Christians), age groups (adults and adolescents), and between nations (Egypt, Turkey, and Kuwait). Table 6 included the structural fit indexes on the four levels (configural, Metric, Scalar, and strict) for each analysis, which did not significantly differ from each other according to the criteria previously discussed in the analysis section.

\subsection{Correlation Results in the Second Sample}

In this dominantly no-faith sample, as expected, interfaith spirituality did not 
Table 6. Multi-group structural invariance of the path model between genders, religious affiliations, regions, age groups (adults and adolescents), and countries in the first sample.

\begin{tabular}{ccccccccc}
\hline \multicolumn{7}{c}{ Multigroup Structural Invariance between genders } \\
& Chi-square & $d f$ & $p$ & chi-squarel dt & CFI & RMSEA & IFI \\
\hline Configural (structure) & 68.305 & 28 & .000 & 2.439 & .937 & .054 & .941 \\
Metric (weights), & 92.118 & 47 & .000 & 1.960 & .929 & .044 & .932 \\
Scalar (intercepts) & 101.863 & 53 & .000 & 1.922 & .923 & .043 & .925 \\
Strict invariance & 105.009 & 59 & .000 & 1.780 & .928 & .040 & .929 \\
\hline Multigroup Structural Invariance between & Christians and Muslims & \\
\hline Configural (structure) & 57.211 & 28 & .001 & 2.043 & .912 & .046 & .915 \\
Metric (weights), & 100.554 & 47 & .000 & 2.139 & .911 & .048 & .915 \\
Scalar (intercepts) & 108.419 & 53 & .000 & 2.046 & .908 & .046 & .911 \\
Strict invariance & 117.993 & 59 & .000 & 2.000 & .902 & .045 & .904 \\
\hline Multigroup Structural & invariance between & adults and adolescents & & \\
\hline Configural (structure) & 53.903 & 28 & .002 & 1.925 & .957 & .044 & .960 \\
Metric (weights), & 66.593 & 47 & .031 & 1.417 & .968 & .029 & .969 \\
Scalar (intercepts) & 77.116 & 53 & .017 & 1.455 & .960 & .031 & .961 \\
Strict invariance & 80.329 & 59 & .034 & 1.362 & .965 & .027 & .966 \\
\hline Multigroup Structural invariance between Egyptians, Turkish and Kuwaitis & \\
\hline Strict invariance & 104.558 & 57 & .000 & 1.834 & .979 & .033 & .964 \\
\hline Metric (weights), & 65.832 & 45 & .023 & 1.463 & .981 & .024 & .969 \\
\hline
\end{tabular}

have the function it has in the faith dominant sample found in the first study. While interfaith spirituality, in this sample was highly correlated with religiosity, it was not correlated with self-esteem, perceived PTG, emotion regulation, or WTELS and was positively correlated with PTSD. However, similar to the first study, WTELS, showed potentially stronger positive correlations with self-esteem, perceived PTG, and reappraisal and lower psychopathology). Table 7 provides the zero-order correlation between the variables and shows the discussed correlations. Further, IFS sub-scales (direct connection, asceticism, meditation, and divine love), in this sample, showed similar no correlation to those found between these variables and the main scale, except for asceticism, that was correlated positively with perceived PTG $(r=.16, p<.05)$ See Table 8 .

\subsection{Path Analysis in the Second Sample}

Consistent with correlational results, in a modified path model, spirituality does not play a significant role in coping with adversities (as predicted in the conceptual model for non-believers). The path model fit well with the data (Chi Square $=19.747$, d.f. $=19, p=.416, \mathrm{CFI}=998, \mathrm{RMSEA}=.015)$. However, in this model, 
Table 7. Zero-order correlation between spirituality and selected variables in the second sample (UK sample).

\begin{tabular}{lcccccccc}
\hline & 1 & 2 & 3 & 4 & 5 & 6 & 7 & 8 \\
\hline 1. Spirituality & 1 & & & & & & & \\
2. self-esteem & -.03 & 1 & & & & & & \\
3. PTG & .06 & $.20^{* * *}$ & 1 & & & & & \\
4. Suppression & .05 & $-.28^{* * *}$ & -.06 & 1 & & & & \\
5. Reappraisal & -.07 & $.28^{* * *}$ & $.30^{* * *}$ & $.24^{* * *}$ & 1 & & & \\
6. EAA & .13 & $-.32^{* * *}$ & .12 & .09 & -.09 & 1 & & \\
7. Will to Live & .04 & $.63^{* * *}$ & $.26^{* *}$ & -.14 & $.41^{* * *}$ & $-.40^{* * *}$ & 1 & \\
8. Religiosity & $.46^{* * *}$ & .02 & .06 & -.04 & -.00 & .02 & -.00 & 1 \\
\hline
\end{tabular}

Notes: ${ }^{*} p<.05,{ }^{* *} p<.01,{ }^{* * *} p<.001$.

Table 8. Zero-order correlations between spirituality and its components and selected variables in the UK sample.

\begin{tabular}{cccccc}
\hline Variables & Direct Connection & Asceticism & Meditation & Divine love & Spirituality \\
\hline Self-esteem & -.042 & .06 & -.06 & -.04 & -.03 \\
Suppression & .07 & .06 & -.01 & .05 & .05 \\
Reappraisal & -.07 & .04 & -.10 & -.09 & -.07 \\
Will to Live & .03 & .10 & .01 & .04 & .04 \\
Religiosity & $.46^{* * *}$ & $.29^{* * *}$ & $.45^{* * *}$ & $.44^{* * *}$ & $.46^{* * *}$ \\
PTG & -.004 & $.16^{*}$ & .08 & .01 & .06 \\
Psychopathology & .09 & .09 & $.20^{* *}$ & .11 & .13 \\
Depression & -.09 & -.08 & -.01 & -.08 & -.07 \\
Suicidality & .06 & .06 & .11 & .05 & .08 \\
\hline
\end{tabular}

Notes: ${ }^{*} p<.05,{ }^{* *} p<.01,{ }^{* * *} p<.001$

as predicted, WTELS played a significant positive role in coping with adversities through reducing EAA, increasing self-esteem, reappraisal, and PTGI scores. For details of the path model, see Figure 3.

\section{Discussion}

In the current research, we developed and tested two structural models for the relationship between interfaith spirituality, life adversities (CST), WTELS, emotion regulation, self-evaluation (i.e., self-esteem), and different aspects of mental health and perceived posttraumatic growth (PTG) in believers and mostly non-believers. We used a combined three samples of believers (Egypt, Turkey, and Kuwait), and one sample of mostly non-believers from the UK to compare the dynamics of spirituality and WTELS in each. The results identified two circuits or trajectories of mental health and posttraumatic growth production that may function similarly or differently in believers and non-believers: The interfaith 


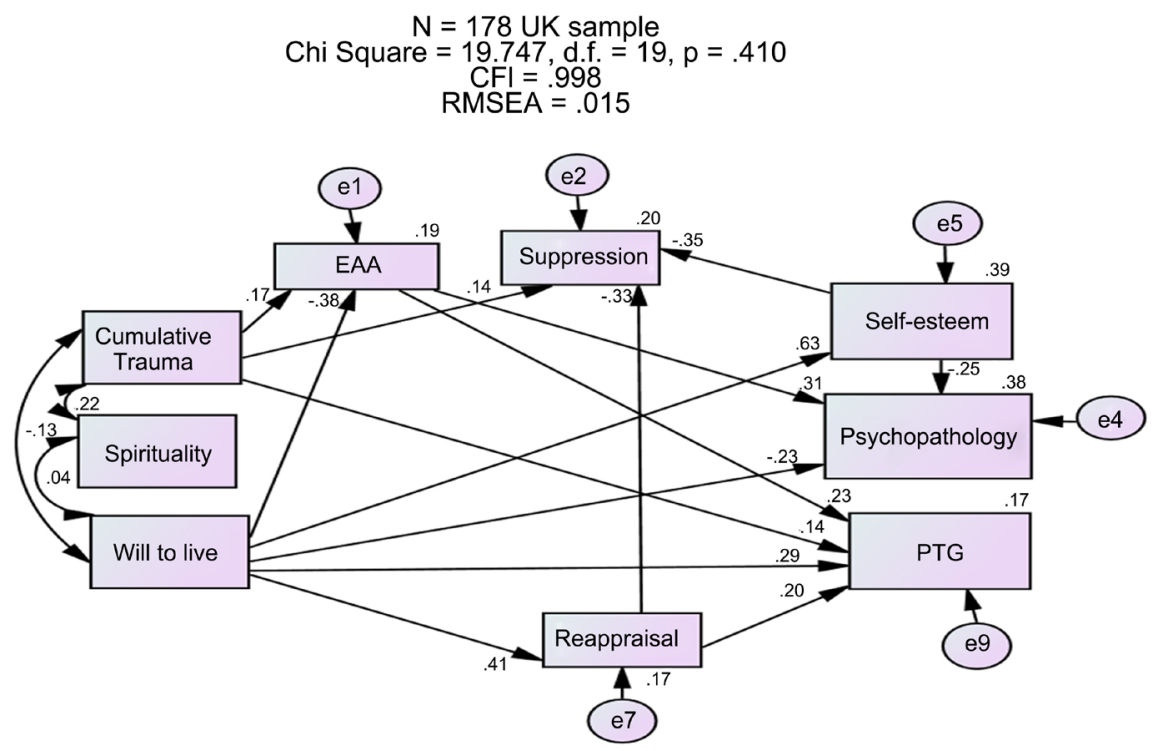

Figure 3. Path Model for the dynamics of coping with life adversities in non-believers (UK sample).

spirituality circuit that is mostly unique to the believers, and the WTELS circuit that is common/shared between believers and non-believers.

The path analysis results provided evidence for the presence of the two different dynamics in faith and non-faith participants. In the first sample of believers, IFS and WTELS both predicted higher self-esteem, reappraisal and posttraumatic growth, and lower EAA and psychopathology. In the second sample of the non-believers, only WTELS was the strong predictor of higher self-esteem, reappraisal and perceived posttraumatic growth, and lower EAA and psychopathology. The results generally confirmed that positive interfaith spirituality dynamics apply only to individuals who believe in a higher power, and generally do not function in the same way in the non-faith group, except for asceticism practices (that implied self-transcendence) that usually do not need a belief in a higher power. The study validated the new model of interfaith spirituality (that included a direct connection with the creator, asceticism, meditation, and divine love) as a critical positive variable in enhancing emotion regulation, self-esteem, and perceived post-traumatic growth and on alleviating the existential anxieties and psychopathology associated with severe identity and cumulative adversities in faith-holding individuals regardless of their faith, gender, or culture.

The correlation between IFS and self-esteem was the highest (.31) in faith groups, while it was not significant in the no-faith group (in contrast to the association between WTELS and self-esteem that was .61 in non-believers, and .44 in believers). Diagnostic criteria and empirical research suggest a significant connection between low self-esteem and psychopathology, especially with depression and anxiety e.g., (Sowislo \& Orth, 2013). Interfaith spirituality involves self-reappraisal as connected to a higher power and the ability to self-transcend. Reappraisal had a significant correlation with IFS in the believers while this rela- 
tionship was not significant in none-believers. Self-reappraisal as related to a higher power may lead to higher positive self-evaluation and higher self-esteem.

Self-transcendence facilitates change in perspective and behavior. Reappraisal of the threats to the person and self, using the new spiritual lens, contributes to relieving the intensity of existential concerns. There is empirical evidence that the meaning found through such existential turmoil predicts unique variance in higher self-esteem, and lower depression and anxiety (Wilt et al., 2021). There is evidence that self-esteem is one of the mediators of the positive effects of spirituality on well-being e.g., (Faull \& Hills, 2004; Joshanloo \& Daemi, 2015).

\subsection{Interfaith Spirituality Circuit and Its Dynamics}

Interfaith spirituality seems to alleviate, in believers, existential anxieties that emerge with adversities and cumulative traumas' existential threats e.g., (Graham et al., 2001). A considerable body of literature provides consistent evidence of the positive correlation between existential interfaith spirituality (IFS) and self-reported, high quality of mental and emotional health e.g., (Exline \& Rose, 2013; Faull et al., 2004; Pargament, 2013; Sawatzky et al., 2005). A meta-analysis (Smith-MacDonald et al., 2017) found that spirituality is associated with lower PTSD, in veterans. Further, a review found empirical evidence of an inverse relationship between spirituality and externalizing disorders in adolescents (Holmes \& Kim-Spoon, 2016). While there is evidence of the inverse relationship between spirituality and varieties of internalizing and externalizing disorders, the evidence in bipolar disorder and schizophrenia (thought disorders) is insufficient e.g., (Bonelli \& Koenig, 2013).

The links between spirituality perceived PTG, and PTSD was intensely researched in the literature. There is replicated evidence of the positive association between spirituality and perceived posttraumatic growth (PTG) e.g., (Pargament et al., 2006). Longitudinal research suggested that perceived and actual growth reflects different dynamics and outcomes. However, the research suggests that the current PTG scale measures perceived (but not actual) growth e.g., (Frazier, et al., 2009). Also, there is evidence of a non-linear quadratic relationship between trauma severity and perceived PTG (Kira, et al., 2013a), and between perceived PTG and PTSD (Kleim \& Ehlers, 2009). There is evidence that striving for high standards in perfectionism literature is positively associated with perceived PTG, while self-discrepancy (e.g., spiritual struggle and moral injury) is negatively associated with perceived PTG e.g., (Shuwiekh et al., 2018). These results suggest a link between interfaith spirituality and personality dynamics of selfdiscrepancy and striving. Future studies may investigate if IFS is associated with the actual or the perceived (potentially illusionary PTG), and probe the potential links between IFS and personality dynamics.

\subsection{WTELS Circuit and Its Dynamics}

WTELS circuitry, while it exists with the same dynamics in the believers, is especially powerful in non-believers and seems to be the strong trajectory that chan- 
nels WTELS positive effects in lowering psychopathology and raising perceived PTG through setting off the same mechanisms of lifting self-esteem and emotion regulation strategy of reappraisal. Reappraisal is a crucial mechanism in the positive effects of cognitive behavior and mindfulness therapies (Garland et al., 2017) and some other therapeutic interventions. Cognitive reappraisal is a commonly used and widely studied emotion regulation strategy that involves re-interpretation of a situation or event to alter its emotional impact (Gross \& John, 2003). Studies support that reappraisal plays an important role in long-term psychological health and the process of meaning-making for a meta-analysis, see (Aldao et al., 2010; Webb et al., 2012). Further, a reappraisal of the event through a new lens helps to recalibrate one's belief and value processing system and life projects accordingly (Aldwin et al., 2014) which contribute to reducing the cognitive dissonance, self-discrepancy, and existential anxiety created by the events. This process positively enhances self-esteem, improves mental health, and facilitates perceived posttraumatic growth, c.f. (Park \& Folkman, 1997). This process can be delineated in the following positive trajectory chain: Trauma $>$ (leads to) increased cognitive and self-discrepancy and existential anxiety (existential turmoil) $>$ initial automatic appraisal $>$ conscious deliberate reappraisal $>$ recalibration of the person's belief and value processing system $>$ decreased cognitive and self-discrepancy and existential anxiety $>$ positive self-evaluation and improved mental health> perceived posttraumatic growth (see Figure 1). This process is active in both circuits of IFS and WTELS in believers and non-believers.

We emphasize the significance of the WTELS circuit in contributing to mental health and PTG in both believers and non-believers. It is for the non-faith/atheists the primary and the strong circuit in coping. There is empirical evidence that the "will to survive" predicts the emergence of different positive coping strategies to oppression (i.e., militancy, political ideology, social support, forgiveness) (Kira et al., 2014a). The existential integrative concept of "Will to exist, live, and survive (WTELS)" is the intrinsic innate meta-motivation to exist, live, survive, self-actualize, and succeed/thrive (Kira et al., 2020e). It is a leading existential meta-motivation that steers the person's specific motivations and related general and specific life goals and objectives. It was found to be highly correlated with resilience and negatively with PTSD, internalizing, externalizing, and thought disorders. (Al-Daylami, 2005), (a Sufi thinker) had associated the instinct to live and exist with spirituality and mystical love.

Testing the effects of spirituality on mixed samples of believers and nonbelievers can be misleading. It is important to develop in future studies measures for secular spirituality that can be tested in believers and non-believers, while interfaith spirituality should be reserved for samples that represent believers from different faiths. This study is the first to demonstrate that the positive effects of interfaith spirituality are present only in the believers, which may be common sense, but have never been addressed or tested in any study we are aware of. 


\subsection{Implications for Clinical Practice}

For faith-holding individuals, spirituality-based theories and practices inspired various therapeutic interventions in the discipline of psychotherapy e.g., (Park \& Slattery, 2013; Post \& Wade, 2009). Spirituality inspired different evidence-based interventions in psychotherapy are emerging. Examples are mindfulness, forgiveness, acceptance and commitment therapy (ACT), meditation, and transcendental meditation c.f., e.g., (Park \& Slattery, 2013; Pargament, 2011). Further, spirituality inspired transcultural psychotherapy that introduced traditional and non-traditional forms of healing that are still developing and promising fields e.g., (Gone, 2010). Spirituality-inspired psychotherapy interventions may be more secular and help cope with extreme stressors and make sense of life and death for believers and non-believers. However, more research is needed to explore its potential differential effectiveness in believers and non-believers. Further, current results found that some elements of interfaith spirituality, i.e., asceticism practice, are still effective coping strategies even for no-faith individuals and need to be developed and tested as a therapeutic intervention. Practicing asceticism is an ignored intervention strategy that can be effective for believers and non-believers.

The study has several potential applications and implications for believers and non-believers. For believers, the four domains of spirituality provide a map that helps to detail and further develop different inter-faith trans-diagnostic spirituality-based interventions related to each domain. That is, especially important for the domains that have been found most relevant to alleviating existential anxieties and relieving depression and psychopathology, and enhancing PTG and positive self-esteem. All spirituality components are significantly positively associated with self-esteem, reappraisal, and suppression. They were significantly negatively associated with externalizing, thought disorder, and depression. However, "direct connection with the Creator" seems to have the strongest negative association with existential concerns (EAA), and depression, and the strongest positive association with self-esteem and will to exist, live and survive.

"Asceticism" seems to have the strongest negative association with internalizing, and thought disorder, and the strongest positive association with emotion regulation. Asceticism is operationally defined as: "Controlling extreme passion for material things, not wasting and get satisfied with little things; Modesty and being realistic and knowing the real value and limits of me; The ability to control my wild desires and craves; Being self-satisfied, grateful and virtuous e.g., being kind, fair, open-minded, having integrity, wisdom, and honesty)" is related to different mental health perspectives including the strength model of self-control and ego depletion (Baumeister, 2002; Baumeister et al., 2007). High self-control predicted good adjustment, less pathology, better grades, and interpersonal success (Tangney et al., 2004). Another related perspective is the conservation of resource theory (Hobfoll, 1989) which is based on the supposition that people strive to retain, protect, and build resources and that what is threatening to them 
is the potential or actual loss of these valued resources. Conservation behavior is found to be related to satisfaction (De Young \& Kaplan, 1985). Another perspective related to asceticism is modesty and other virtues which all are among the signature strengths highlighted in the positive psychology movement and all proved to have positive mental health outcomes (Seligman et al., 2005).

"Meditation" seems to have the strongest association with PTG, as well as a strong association with the emotion regulation strategy of reappraisal. Different meditation approaches were used to increase awareness and provide more veridical perception, reduce negative affect and improve vitality and coping, and improve stress-related outcomes (anxiety, depression, stress/distress, positive mood, mental health-related quality of life, attention, substance use, eating habits, sleep, pain, and weight) in diverse adult clinical populations. Results of meta-analyses provided evidence of a small to moderate effect size of its effectiveness e.g., (Eberth \& Sedlmeier, 2012; Goyal et al., 2014; Sedlmeier et al., 2012).

"Divine love" seems to have the strongest negative association with suicidality and externalizing behavior and has a strong negative association with EAA, and positive association with "will to exist live and survive". This differential strength of potential effects of each component of spirituality may help individualize interventions and developing a flexible package for an inter-faith spirituality intervention model that utilizes flexibly its different components according to each client's specific clinical needs. Mindfulness, forgiveness, and acceptance and commitment, and meditation and transcendental meditation may be developed as part of a more comprehensive intervention model that utilizes the components of spirituality for believers and non-believers.

Further, combining spirituality intervention with an intervention that targets "will to exist, live and survive" (WTELS) can increase its total effectiveness, as WTELS has comparable strong positive effects on mental health and perceived PTG. Future research needs to explore more and replicate the potential differential contribution of each component of spirituality and the combination of spirituality and WTELS interventions. The shared WTELS circuit between believers and non-believers found in the results may be translated into WTELS-focused intervention for believers and non-believers. The potential effectiveness of the designed spirituality and will-to-live based intervention and prevention programs can be tested in controlled trials.

\section{Conclusion}

To recap, these findings suggest the existence of two strong positive trajectories to mental health and PTG: Interfaith spirituality and WTELS. Both are existent in faith-holding individuals, while the WTELS pathway is the prime pathway for non-faith individuals. Both pathways, in believers, had direct and indirect negative effects on psychopathology, and positive effects on PTG, and their indirect effects on psychopathology and PTG were mediated by self-esteem and reappraisal. These findings suggest that focusing on cultivating spirituality in indi- 
viduals who believe in a higher power, in addition to WTELS, has the promise of significant healing and growth. However, more future research is needed to be able to replicate these findings and generalize these conclusions and develop effective prevention and intervention strategies tailored to the person's belief system as well as transdiagnostic interventions to enhance and optimize the person's WTELS.

\section{Limitations of the Study}

The current study has several limitations. One of the limitations is that the study was conducted in a convenient non-clinical sample that may have limited and biased representation. We recommend more studies that use more representative clinical and non-clinical samples. Another relatively important issue is related to the composition of the second sample. While the second sample included over $70 \%$ of non-believers, it included $24 \%$ of Christians which may make the results limited in its scope. Another limitation is that the measures we used are based on participants' self-reports, which could be subject to under-or over-reporting of events due to current symptoms, embarrassment, shame, or social desirability. Another limitation is that the study utilized a cross-sectional design in testing the mediated model. Mediated models contain causal paths that inherently involve the passage of time and testing these paths with cross-sectional data can produce biased estimates (Maxwell \& Cole, 2007). Future studies may use longitudinal studies if feasible to retest the proposed model. Additionally, we should caution that the use of terms like direct, indirect, and total effects should be understood as they were meant and intended in their use in path analysis. Further, we have to exercise caution in interpreting the path model for the UK sample, as the sample size does not provide strong power. Additionally, while the measures we utilized were scientifically translated to the Turkish language, but they have never been validated on Turkish populations except for the cumulative trauma scale (Eltan, 2019).

\section{Conflicts of Interest}

The authors declare no conflicts of interest regarding the publication of this paper.

\section{References}

Aldao, A., Nolen-Hoeksema, S., \& Schweizer, S. (2010). Emotion Regulation Strategies across Psychopathology: A Meta-Analytic Review. Clinical Psychology Review, 30, 217-237. https://doi.org/10.1016/j.cpr.2009.11.004

Al-Daylami, A. (2005). A Treatise on Mystical Love. J. N. Bell, \& M. A. L. Al Shafijie (Trans.), Edinburgh: Edinburgh University Press.

Aldwin, C. M., Park, C. L., Jeong, Y.-J., \& Nath, R. (2014). Differing Pathways between Religiousness, Spirituality, and Health: A Self-Regulation Perspective. Psychology of Religion and Spirituality, 6, 9-21. https://doi.apa.org/doi/10.1037/a0034416

Al-Ibraheem, B., Kira, I., Aljakoub, J., \& Al-Ibraheem, A. (2017). The Health Effect of the 
Syrian Conflict on IDPs and Refugees. Peace and Conflict: Journal of Peace Psychology, 23, 140-152. https://doi.apa.org/doi/10.1037/pac0000247

Baumeister, R. F. (2002). Ego Depletion and Self-Control Failure: An Energy Model of the Self's Executive Function. Self and Identity, 1, 129-136. https://doi.org/10.1080/152988602317319302

Baumeister, R. F., Vohs, K. D., \& Tice, D. M. (2007). The Strength Model of Self-Control. Current Directions in Psychological Science, 16, 351-355.

https://doi.org/10.1111\%2Fj.1467-8721.2007.00534.x

Blake, D. D., Weathers, F. W., Nagy, L. M., Kaloupek, D. G., Gusman, F. D., Charney, D. S., \& Keane, T. M. (1995). The Development of a Clinician-Administered PTSD Scale. Journal of Traumatic Stress, 8, 75-90. https://doi.org/10.1002/jts.2490080106

Bonelli, R. M., \& Koenig, H. G. (2013). Mental Disorders, Religion and Spirituality 1990 to 2010: A Systematic Evidence-Based Review. Journal of Religion and Health, 52, 657-673. https://doi.org/10.1007/s10943-013-9691-4

Byrne, B. M. (2012). Choosing Structural Equation Modeling Computer Software: Snapshots of LISREL, EQS, AMOS, and Mplus. In R. H. Hoyle (Ed.), Handbook of Structural Equation Modeling (pp. 307-324). New York, NY: The Guilford Press.

Byrne, B. M., Shavelson, R. J., \& Muthén, B. (1989). Testing for the Equivalence of Factor Covariance and Mean Structures: The Issue of Partial Measurement Invariance. Psychological Bulletin, 105, 456-466. https://doi.apa.org/doi/10.1037/0033-2909.105.3.456

Caspi, A., Houts, R. M., Belsky, D. W., Goldman-Mellor, S. J., Harrington, H., Israel, S. et al. (2014). The P Factor: One General Psychopathology Factor in the Structure of Psychiatric Disorders? Clinical Psychological Science, 2, 119-137. https://doi.org/10.1177\%2F2167702613497473

Chen, F. F. (2007). Sensitivity of Goodness of Fit Indexes to Lack of Measurement Invariance. Structural Equation Modeling: A Multidisciplinary Journal, 14, 464-504. https://doi.org/10.1080/10705510701301834

Chochinov, H. M., Wilson, K. G., Enns, M., \& Lander, S. (1997). Are You Depressed? Screening for Depression in the Terminally ill. American Journal of Psychiatry, 154, 674-676. https://doi.org/10.1176/ajp.154.5.674

Davis, T. L., Kerr, B. A., \& Kurpius, S. E. R. (2003). Meaning, Purpose, and Religiosity in At-Risk Youth: The Relationship between Anxiety and Spirituality. Journal of Psychology and Theology, 31, 356-365. https://doi.org/10.1177\%2F009164710303100406

De Young, R., \& S. Kaplan (1985) Conservation Behavior and the Structure of Satisfactions. Journal of Environmental Systems, 15, 233-242. https://doi.org/10.2190/R4QK-MU4Q-G7W1-MFVU

Dennis, M. L., Chan, Y. F., \& Funk, R. R. (2006). Development and validation of the GAIN Short Screener (GSS) for internalizing, externalizing and substance use disorders and crime/violence problems among adolescents and adults. The American Journal on Addictions, 15, s80-s91. https://doi.org/10.1080/10550490601006055

Eberth, J., \& Sedlmeier, P. (2012). The Effects of Mindfulness Meditation: A Meta-Analysis. Mindfulness, 3, 174-189. https://doi.org/10.1007/s12671-012-0101-x

Eltan, S. (2019). Psychometric Properties of the Cumulative Trauma Scale: Evaluation of the Reliability and Validity in a Turkish Sample. A Thesis Submitted to Graduate School of Social Science, Ankara: Middle East Technical University.

Emmons, R. A. (2005). Striving for the Sacred: Personal Goals, Life Meaning, and Religion. Journal of Social Issues, 61, 731-745. 
https://doi.org/10.1111/j.1540-4560.2005.00429.x

Exline, J. J., \& Rose, E. D. (2013). Religious and Spiritual Struggles. In R. F. Paloutzian \& C. L. Park (Eds.), Handbook of the Psychology of Religion and Spirituality (pp. 380-398). New York, NY: The Guilford Press.

Faull, K., Hills, M. D., Cochrane, G., Gray, J., Hunt, M., McKenzie, C., \& Winter, L. (2004). Investigation of Health Perspectives of Those with Physical Disabilities: The Role of Spirituality as a Determinant of Health. Disability and Rehabilitation, 26, 129-144. https://doi.org/10.1080/09638280310001636419

Frankl, V. E. (2000). Man’s Search for Ultimate Meaning. New York, NY: Basic Books. (First published 1948).

Frazier, P., Tennen, H., Gavian, M., Park, C., Tomich, P., \& Tashiro, T. (2009). Does Self-Reported Posttraumatic Growth Reflect Genuine Positive Change? Psychological Science, 20, 912-919. https://doi.org/10.1111\%2Fj.1467-9280.2009.02381.x

Garland, E. L., Kiken, L. G., Faurot, K., Palsson, O., \& Gaylord, S. A. (2017). Upward Spirals of Mindfulness and Reappraisal: Testing the Mindfulness-to-Meaning Theory with Autoregressive Latent Trajectory Modeling. Cognitive Therapy and Research, 41, 381-392. https://doi.org/10.1007/s10608-016-9768-y

Gillespie, G. L., \& Gates, D. M. (2013). Using Proactive Coping to Manage the Stress of Trauma Patient Care. Journal of Trauma Nursing, 20, 44-50. https://doi.org/10.1097/JTN.0b013e318286608e

Gone, J. P. (2010). Psychotherapy and Traditional Healing for American Indians: Exploring the Prospects for Therapeutic Integration. The Counseling Psychologist, 38, 166-235. https://doi.org/10.1177\%2F0011000008330831

Goyal, M., Singh, S., Sibinga, E. M., Gould, N. F., Rowland-Seymour, A., Sharma, R. et al. (2014). Meditation Programs for Psychological Stress and Well-Being: A Systematic Review and Meta-Analysis. JAMA Internal Medicine, 174, 357-368. https://doi.org/10.1001/jamainternmed.2013.13018

Graham, S., Furr, S., Flowers, C., \& Burke, M. T. (2001). Research and Theory Religion and Spirituality in Coping with Stress. Counseling and Values, 46, 2-13. https://doi.org/10.1002/j.2161-007X.2001.tb00202.x

Gross, J. J., \& John, O. P. (2003). Individual Differences in Two Emotion Regulation Processes: Implications for Affect, Relationships, and Well-Being. Journal of Personality and Social Psychology, 85, 348-362. https://doi.apa.org/doi/10.1037/0022-3514.85.2.348

Hayes, A. F. (2013). Introduction to Mediation, Moderation, and Conditional Process Analysis. A Regression-Based Approach. New York, NY: Guilford.

Head, D., Singh, T., \& Bugg, J. M. (2012). The Moderating Role of Exercise on StressRelated Effects on the Hippocampus and Memory in Later Adulthood. Neuropsychology, 26, 133-143. https://doi.apa.org/doi/10.1037/a0027108

Hill, P. C., Pargament, K. I., Hood, R. W., McCullough Jr, M. E., Swyers, J. P., Larson, D. B., \& Zinnbauer, B. J. (2000). Conceptualizing Religion and Spirituality: Points of Commonality, Points of Departure. Journal for the Theory of Social Behaviour, 30, 51-77. https://doi.org/10.1111/1468-5914.00119

Hobfoll, S. E. (1989). Conservation of Resources: A New Attempt at Conceptualizing Stress. American Psychologist, 44, 513-524. https://doi.apa.org/doi/10.1037/0003-066X.44.3.513

Holmes, C., \& Kim-Spoon, J. (2016). Why Are Religiousness and Spirituality Associated with Externalizing Psychopathology? A Literature Review. Clinical Child and Family 
Psychology Review, 19, 1-20. https://doi.org/10.1007/s10567-015-0199-1

John, O. P., \& Gross, J. J. (2004). Healthy and Unhealthy Emotion Regulation: Personality Processes, Individual Differences, and Lifespan Development. Journal of Personality, 72, 1301-1334. https://doi.org/10.1111/j.1467-6494.2004.00298.x

Joshanloo, M., \& Daemi, F. (2015). Self-Esteem Mediates the Relationship between Spirituality and Subjective Well-Being in Iran. International Journal of Psychology, 50, 115-120. https://doi.org/10.1002/ijop.12061

Kanaan, A., Kira, I., Shuwiekh, H., Kucharska, J., \& Al-Huwailah, A. (2019). The Dynamics behind Low Posttraumatic Growth in Victims of Type III Traumas: The Case of Syrians and Palestinians. Traumatology, 26, 205-214. https://doi.apa.org/doi/10.1037/trm0000229

Kira, I (2010). Etiology and Treatments of Post-Cumulative Traumatic Stress Disorders in Different Cultures. Traumatology, 16, 128-141. https://doi.apa.org/doi/10.1177/1534765610365914

Kira, I. A. (2001). Taxonomy of Trauma and Trauma Assessment. Traumatology, 7, 73-86. https://doi.apa.org/doi/10.1177/153476560100700202

Kira, I. A., \& Shuwiekh, H. (2021). Discrimination and Mental Health of Christians in Egypt: Coping Trajectories and Perceived Posttraumatic Growth. Mental Health, Religion \& Culture, 24, 1-22. https://doi.org/10.1080/13674676.2020.1832454

Kira, I. A., Ashby, J. S., Odenat, L., \& Lewandowski, L. (2013d). The Mental Health Effects of Torture trauma and its Severity: A Replication and Extension. Psychology, 4, 472-482. https://doi.org/10.4236/psych.2013.45067

Kira, I. A., Lewandowski, L., Templin, T., Ramaswamy, V., Ozkan, B., \& Mohanesh, J. (2008a). Measuring Cumulative Trauma Dose, Types, and Profiles Using a Development-Based Taxonomy of Traumas. Traumatology, 14, 62-87. https://doi.apa.org/doi/10.1177/1534765608319324

Kira, I. A., Omidy, A. Z., \& Ashby, J. S. (2014c). Cumulative Trauma, Appraisal, and Coping in Palestinian and American Indian Adults: Two Cross-Cultural Studies. Traumatology, 20, 119-133. https://doi.apa.org/doi/10.1037/h0099397

Kira, I. A., Özcan, N. A., Shuwiekh, H., Kucharska, J., Al-Huwailah, A., \& Kanaan, A. (2020b) The Compelling Dynamics of "Will to Exist, Live and Survive" on Effecting PTG upon Exposure to Adversities: Is It Mediated, in Part, by Emotional Regulation, Resilience, and Spirituality. Traumatology: An International Journal, 26, 405-419. https://doi.apa.org/doi/10.1037/trm0000263

Kira, I. A., Shuwiekh, H., \& Kucharska, J. (2017). Screening for Psychopathology Using the Three Factors Model of the Structure of Psychopathology: A Modified Form of GAIN Short Screener. Psychology, 8, 2410-2427.

https://doi.org/10.4236/psych.2017.814152

Kira, I. A., Shuwiekh, H., Kucharska, J., Al-Huwailah, A. H., \& Moustafa, A. (2020e). "Will to Exist, Live and Survive" (WTELS): Measuring Its Role as Master/Metamotivator and in Resisting Oppression and Related Adversities. Peace and Conflict: Journal of Peace Psychology, 26, 47-61. https://doi.apa.org/doi/10.1037/pac0000411

Kira, I. A., Shuwiekh, H., Kucharska, J., Fawzi, M., Ashby, J. S., Omidy, A. Z., AbouMediene, S., \& Lewandowski, L. (2018a). Trauma Proliferation and Stress Generation (TPSG) Dynamics and Their Implications for Clinical Science. American Journal of Orthopsychiatry, 85, 582-596.

https://doi.apa.org/doi/10.1037/ort0000304 
Kira, I. A., Templin, T., Lewandowski, L., \& Shuwiekh, H. (2018b). A Conceptual Model and Measurement of Identity-Based, Existential Annihilation Anxieties (EAA). Psychology, 9, 1306-1328. https://doi.org/10.4236/psych.2018.96080

Kira, I., Abou-Mediene, S., Ashby, J., Lewandowski, L., Mohanesh, J., \& Odenat, L. (2012a). Post-Traumatic Growth Inventory: Psychometric Properties of the Arabic Version in Palestinian Adults. The International Journal of Educational and Psychological Assessment, 11, 120-137.

Kira, I., Abou-Mediene, S., Ashby, J., Odenat, L., Mohanesh, J., \& Alamia, H. (2013a). The Dynamics of Post-traumatic Growth across Different Trauma Types in a Palestinian Sample. Journal of Loss and Trauma: International Perspectives on Stress \& Coping, 18, 120-139. https://doi.org/10.1080/15325024.2012.679129

Kira, I., Alawneh, A., Aboumediene, S., Lewandowski, L., \& Laddis, A. (2014a). Dynamics of Oppression and Coping from Traumatology Perspective: The Example of Palestinian Youth. Peace and Conflict: Journal of Peace Psychology, 20, 385-411. https://doi.apa.org/doi/10.1037/pac0000053

Kira, I., Ashby, J. S., Lewandowski, L., Alawneh, A.N., Mohanesh, J., \& Odenat, L. (2013b). Advances in Continuous Traumatic Stress Theory: Traumatogenic Dynamics and Consequences of Intergroup Conflict: The Palestinian Adolescents case. Psychology, 4, 396-409. https://doi.org/10.4236/psych.2013.44057

Kira, I., Barger, B., Shuwiekh, H., Kucharska, J., \& Al-Huwailah, A. H. (2019a). Cumulative Stressors and Traumas and Suicide: A Non-Linear Cusp Dynamic Systems Model. Psychology, 10, 1999-2018. https://doi.org/10.4236/psych.2019.1015128

Kira, I., Barger, B., Shuwiekh, H., Kucharska, J., \& Al-Huwailah, A. (2020a). The Threshold Non-Linear Model for the Effects of Cumulative Stressors and Traumas: A Chained Cusp Catastrophe Analysis. Psychology, 11, 385-403.

https://doi.org/10.4236/psych.2020.113025

Kira, I., Fawzi, M., \& Fawzi, M. (2013c). The Dynamics of Cumulative Trauma and Trauma Types in Adults Patients with Psychiatric Disorders: Two Cross-Cultural Studies. Traumatology: An International Journal, 19, 179-195. https://doi.apa.org/doi/10.1177/1534765612459892

Kira, I., Lewandowski, L., Chiodo, L., \& Ibrahim, A. (2014b). Advances in Systemic Trauma Theory: Traumatogenic Dynamics and Consequences of Backlash as a Multi-Systemic Trauma on Iraqi Refugee Muslim Adolescents. Psychology, 5, 389-412. https://doi.org/10.4236/psych.2014.55050

Kira, I., Lewandowski, L., Somers, C., Yoon, J., \& Chiodo, L. (2012b) PTSD, Trauma Types, Cumulative Trauma, and IQ: The Case of African American and Iraqi Refugee Adolescents. Psychological Trauma: Theory, Research, Practice, and Policy, 4, 128-139. https://doi.apa.org/doi/10.1037/a0022121

Kira, I., Shuwiekh, H., Al-Huwailah, A. H., Zidan, T., \& Bujold-Bugeaud, M. (2019c). Measuring Interfaith Spirituality: Initial Validation and Psychometrics. Psychology of Religion and Spirituality. Advance Online Publication. https://doi.apa.org/doi/10.1037/rel0000242

Kira, I., Shuwiekh, H., Al-Huwailah, A., Elwakeel, S., Waheep, N., Ebada, E., \& Ibrahim, E. (2020c). The Direct and Indirect Impact of Trauma Types and Cumulative Stressors and Traumas on Executive Functions. Journal of Applied Neuropsychology: Adult. https://doi.org/10.1080/23279095.2020.1848835

Kira, I., Shuwiekh, H., Kucharska, J., \& Al-Huwailah, A. (2019b). The Integrated Structural and Measurement Models of Existential Annihilation Anxieties (EAA) and Their Potential Contribution to Clinical Science: Two Studies. Psychology, 10, 449-480.

https://doi.org/10.4236/psych.2019.104031 
Kira, I., Shuwiekh, H., Rice, K., Ashby, J.S., Alhuwailah, A., Sous, M., Baali, S., Azdaou, C., Oliemat, E., \& Jamil, H. (2021). Coping with COVID-19 Continuous Complex Stressors: The "Will to Exist Live, and Survive" and Perfectionistic Striving. Traumatology: An International Journal. (In Press)

Kira, I., Smith, I., Lewandowski, L., \& Templin, T. (2010).The Effects of Perceived Gender Discrimination on Refugee Torture Survivors: A Cross-Cultural Traumatology Perspective. Journal of the American Psychiatric Nurses Association, 16, 299-306.

https://doi.org/10.1177\%2F1078390310384401

Kira, I., Templin, T., Lewandowski, L., Ramaswamy, V., Bulent, O., Mohanesh, J., \& Abdulkhaleq, H. (2012c). Collective and Personal Annihilation Anxiety: Measuring Annihilation Anxiety AA. Psychology, 3, 90-99. https://doi.org/10.4236/psych.2012.31015

Kira, I.A. (2021). Taxonomy of Stressors and Traumas: An Update of the Development-Based Trauma Framework (DBTF): A Life-Course Perspective on Stress and Trauma. Traumatology, Advance Online Publication. https://doi.apa.org/doi/10.1037/trm0000305

Kleim, B., \& Ehlers, A. (2009). Evidence for a Curvilinear Relationship between Posttraumatic Growth and Posttrauma Depression and PTSD in Assault Survivors. Journal of Traumatic Stress, 22, 45-52. https://doi.org/10.1002/jts.20378

Koltko-Rivera, M. E. (2006). Rediscovering the Later Version of Maslow's Hierarchy of Needs: Self-Transcendence and Opportunities for Theory, Research, and Unification. Review of General Psychology, 10, 302-317. https://doi.org/10.1037\%2F1089-2680.10.4.302

Laceulle, O. M., Vollebergh, W. A. M., \& Ormel, J. (2015). The Structure of Psychopathology in Adolescence: Replication of a General Psychopathology Factor in the TRAILS Study. Clinical Psychological Science, 3, 850-860. https://doi.org/10.1177\%2F2167702614560750

Levenson, M. R., Jennings, P. A., Aldwin, C. M., \& Shiraishi, R. W. (2005). SelfTranscendence: Conceptualization and Measurement. The International Journal of Aging and Human Development, 60, 127-143. https://doi.org/10.2190\%2FXRXM-FYRA-7U0X-GRC0

Maxwell, S. E., \& Cole, D. A. (2007). Bias in Cross-Sectional Analyses of Longitudinal Mediation. Psychological Methods, 12, 23-44. https://doi.apa.org/doi/10.1037/1082-989X.12.1.23

Meade, A. W., \& Lautenschlager, G. J. (2004). A Monte-Carlo Study of Confirmatory Factor Analytic Tests of Measurement Equivalence/Invariance. Structural Equation Modeling, 11, 60-72. https://doi.org/10.1207/S15328007SEM1101_5

Millender, E. I. (2013). Cumulative Trauma among Adult Mayas Living in Southeast Florida. Ph.D. Dissertation, Boca Raton, FL: Florida Atlantic University, 196 p.

Omidy, A. Z. (2012). Influence of Cumulative Trauma, Binge Eating, and Coping Styles on the General Health of American Indians (Doctoral Dissertation). Norman, OK: University of Oklahoma.

Pargament, K. I. (1999). The Psychology of Religion and Spirituality? Yes and No. The International Journal for the Psychology of Religion, 9, 3-16. https://doi.org/10.1207/s15327582ijpr0901_2

Pargament, K. I. (2011). Spiritually Integrated Psychotherapy: Understanding and Addressing the Sacred. New York, NY: Guilford Press.

Pargament, K. I. (2013). Spirituality as an Irreducible Human Motivation and Process. International Journal for the Psychology of Religion, 23, 271-281.

https://doi.org/10.1080/10508619.2013.795815 
Pargament, K. I., Desai, K. M., McConnell, K. M., Calhoun, L. G., \& Tedeschi, R. G. (2006). Spirituality: A Pathway to Posttraumatic Growth or Decline. In L. G. Calhoun, \& R. G. Tedeschi (Eds.), Handbook of Posttraumatic Growth: Research and Practice (pp. 121-137). New York: Routledge.

Park, C. L., \& Folkman, S. (1997). Meaning in the Context of Stress and Coping. Review of General Psychology, 1, 115-144. https://doi.org/10.1037\%2F1089-2680.1.2.115

Park, C. L., \& Slattery, J. M. (2013). Religion, Spirituality, and Mental Health. In R. F. Paloutzian, C. L. Park, R. F. Paloutzian, \& C. L. Park (Eds.), Handbook of the Psychology of Religion and Spirituality (2nd ed., pp. 540-599). New York, NY: Guilford Press.

Park, C. L., Masters, K. S., Salsman, J. M., Wachholtz, A., Clements, A. D., Salmoirago-Blotcher, E. et al. (2017). Advancing Our Understanding of Religion and Spirituality in the Context of Behavioral Medicine. Journal of Behavioral Medicine, 40, 39-51. https://doi.org/10.1007/s10865-016-9755-5

Post, B. C., \& Wade, N. G. (2009). Religion and Spirituality in Psychotherapy: A Practice-Friendly Review of Research. Journal of clinical psychology, 65, 131-146. https://doi.org/10.1002/jclp.20563

Rizeq, J., Flora, D. B., \& McCann, D. (2018). Construct Validation of the Trauma Symptom Checklist-40 Total and Subscale Scores. Assessment, 27, 1016-1028. https://doi.org/10.1177\%2F1073191118791042

Rosenberg, M. (2015). The Measurement of Self-Esteem, Society, and the Adolescent Self-Image. In editor, Society and the Adolescent Self-Image Princeton (pp. 16-36). Princeton, NJ: Princeton University Press. https://doi.org/10.1515/9781400876136-003

Sarstedt, M., Henseler, J., \& Ringle, C. M. (2011). Multigroup Analysis in Partial Least Squares (PLS) Path Modeling: Alternative Methods and Empirical Results. In: M. Sarstedt, M. Schwaiger, \& C. R. Taylor (Eds.), Measurement and Research Methods in International Marketing (Vol. 22, pp. 195-218). Bingley: Emerald Group Publishing Limited. https://doi.org/10.1108/S1474-7979(2011)0000022012

Sawatzky, R., Ratner, P. A., \& Chiu, L. (2005). A Meta-Analysis of the Relationship between Spirituality and Quality of Life. Social Indicators Research, 72, 153-188. https://doi.org/10.1007/s11205-004-5577-x

Sedlmeier, P., Eberth, J., Schwarz, M., Zimmermann, D., Haarig, F., Jaeger, S., \& Kunze, S. (2012). The Psychological Effects of Meditation: A Meta-Analysis. Psychological Bulletin, 138, 1139-1171. https://doi.apa.org/doi/10.1037/a0028168

Seligman, M. E. P., Steen, T. A., Park, N., \& Peterson, C. (2005). Positive Psychology Progress: Empirical Validation of Interventions. American Psychologist, 60, 410-421. https://doi.apa.org/doi/10.1037/0003-066X.60.5.410

Shuwiekh, H., Kira, I. A., \& Ashby, J. S. (2018). What Are the Personality and Trauma Dynamics That Contribute to Posttraumatic Growth? International Journal of Stress Management, 25, 181-194. https://doi.apa.org/doi/10.1037/str0000054

Smith-MacDonald, L., Norris, J. M., Raffin-Bouchal, S., \& Sinclair, S. (2017). Spirituality and Mental Well-Being in Combat Veterans: A Systematic Review. Military Medicine, 182, e1920-e1940. https://doi.org/10.7205/MILMED-D-17-00099

Sowislo, J. F., \& Orth, U. (2013). Does Low Self-Esteem Predict Depression and Anxiety? A Meta-Analysis of Longitudinal Studies. Psychological Bulletin, 139, 213-240. https://doi.apa.org/doi/10.1037/a0028931

Tangney, J. P., Baumeister, R. F., \& Boone, A. L. (2004). High Self-Control Predicts Good Adjustment, Less Pathology, Better Grades, and Interpersonal Success. Journal of Personality, 72, 271-324. https://doi.org/10.1111/j.0022-3506.2004.00263.x 
Tedeschi, R. G., \& Calhoun, L. G. (1996). The Posttraumatic Growth Inventory: Measuring the Positive Legacy of Trauma. Journal of Traumatic Stress, 9, 455-471. https://doi.org/10.1002/jts.2490090305

Van de Schoot, R., Lugtig, P., \& Hox, J. (2012). A Checklist for Testing Measurement Invariance. European Journal of Developmental Psychology, 9, 486-492. https://doi.org/10.1080/17405629.2012.686740

Weathers, F. W., Keane, T. M., \& Davidson, J. R. (2001). Clinician-Administered PTSD Scale: A review of the first ten years of research. Depression and anxiety, 13, 132-156. https://doi.org/10.1002/da.1029

Webb, T. L., Miles, E., \& Sheeran, P. (2012). Dealing with Feeling: A Meta-Analysis of the Effectiveness of Strategies Derived from the Process Model of Emotion Regulation. Psychological Bulletin, 138, 775-808. https://doi.apa.org/doi/10.1037/a0027600

Wilt, J. A., Grubbs, J. B., Exline, J. J., \& Pargament, K. I. (2021). Authenticity, Presence of Meaning, and Struggle with Ultimate Meaning: Nuanced Between- and Within-Person Associations. Journal of Research in Personality, 93, Article ID: 104104.

https://doi.org/10.1016/j.jrp.2021.104104 